\title{
Reticulate Evolution Everywhere
}

\author{
Nathalie Gontier
}

\begin{abstract}
Reticulation is a recurring evolutionary pattern found in phylogenetic reconstructions of life. The pattern results from how species interact and evolve by mechanisms and processes including symbiosis; symbiogenesis; lateral gene transfer (that occurs via bacterial conjugation, transformation, transduction, Gene Transfer Agents, or the movements of transposons, retrotransposons, and other mobile genetic elements); hybridization or divergence with gene flow; and infectious heredity (induced either directly by bacteria, bacteriophages, viruses, prions, protozoa and fungi, or via vectors that transmit these pathogens). Research on reticulate evolution today takes on inter- and transdisciplinary proportions and is able to unite distinct research fields ranging from microbiology and molecular genetics to evolutionary biology and the biomedical sciences. This chapter summarizes the main principles of the diverse reticulate evolutionary mechanisms and situates them into the chapters that make up this volume.
\end{abstract}

Keywords Reticulate evolution - Symbiosis - Symbiogenesis - Lateral Gene Transfer - Infectious agents - Microbiome - Viriome - Virolution • Hybridization • Divergence with gene flow $•$ Evolutionary patterns $•$ Extended Synthesis

\section{Reticulate Evolution: Patterns, Processes, Mechanisms}

According to the Online Etymology Dictionary (http://www.etymonline.com), the word reticulate is an adjective that stems from the Latin words "rêticulātus" (having a net-like pattern) and rêticulum (little net). When scholars identify the evolution of life as being "reticulated," they first and foremost refer to a recurring evolutionary pattern.

\footnotetext{
N. Gontier $(\bowtie)$

AppEEL_Applied Evolutionary Epistemology Lab, University of Lisbon, Lisbon, Portugal e-mail: nlgontier@fc.ul.pt
} 
Net(work)-like patterns can be found in the way organisms belonging to distinct groups, species, or higher ranks of life interact with other such entities and exchange material and energy at a biochemical, behavioral, sexual or ecological level; as well as in the phylogenetic reconstructions of life's evolved lineages that scholars obtain by comparing the genes, proteins, and overall morphological and behavioral features of organisms and species.

Reticulate evolution brings forth rapid evolutionary change characterized by a network-like pattern of horizontal crossings and mergings that often precede a pattern of vertical descent with modification. This contradicts standard neo-Darwinian evolutionary theory that understands life to evolve gradually by means of natural selection that brings forth a bifurcating or ramificating pattern.

To understand why and how evolution is reticulate in mode and pattern, and why the tempo of reticulate evolution is often fast and non-gradual, scholars have to determine the processes and mechanisms that bring forth these reticulate evolutionary patterns. From the nineteenth century onwards, and mostly from outside or within the margins of the Darwinian and neo-Darwinian paradigm, botanists, microbiologists, bacteriologists, cytologists, and molecular geneticists have been increasingly able to identify these mechanisms and processes. Reticulate evolution today is a vernacular concept for evolutionary change induced by mechanisms and processes of symbiosis, symbiogenesis, lateral gene transfer, hybridization or divergence with gene flow, and infectious heredity.

\subsection{Symbiosis}

The concept of symbiosis was introduced in botany by de Bary (1878) who defined symbiosis as "the living together of unlike-named organisms." de Bary was inspired by the zoologist Van Beneden $(1873,1875)$, who a couple of years earlier had distinguished between "commensalism," "mutualism," and "parasitism" to characterize the "social lives" of animals.

Symbiosis thus refers to species interactions, and symbiotic associations have been mostly studied from within ecological research fields (Buchner 1921, 1939; Paracer and Ahmadjian 1986; Sapp 1994). Distinct organisms interact by providing a habitat or ecological niche for one another, by serving as a nutritional source, by enabling reproduction (in the case of pollination, for example), or by providing metabolic functions, morphological traits, and behavioral features neither of the partners are able to develop on their own. When organisms engage in a symbiotic association, both the host (the larger partner in the association) and the symbiont $(s)$ (the smaller partner) often develop new features and sometimes form new individuals with characteristics not found in the individual organisms (Margulis 1991, 1998). Lichens, for example, result from a conjunctive symbiosis between a fungus (the mycobiont) and algae or cyanobacteria (the phycobiont).

Symbiosis can be temporary and facultative or extend prolonged periods of time, sometimes resulting in obligate and hereditary symbiosis (Buchner 1921, 
1939; Wallin 1927; Lederberg 1952; Sagan 1967). When distinct organisms live on the surface of other organisms (on their skin, the leafs or roots of plants, the gill of fish, the outer membrane of cells), the symbiosis is called ectosymbiosis; and when organisms live inside other living organisms (inside the cells, leaf cavities or roots of legumes, or inside the vascular, lymphatic or gastro-intestinal systems), it is called endosymbiosis. Symbiotic associations are also differentiated based upon actual (penetrating) physical contact between the host and symbiont (conjunctive symbiosis), or the mere living inside each other's vicinity (disjunctive symbiosis) (Albany 1998).

Symbiotic associations can be acquired by horizontal or vertical transmission (outside or via the germline) (Archibald 2014; Douglas 2010; Gontier forthcoming). And although symbiosis per definition defines symbiotic relations to occur between living organisms, also viruses (genetic agents) and prions (infectious proteins) can be understood as symbiotic partners although neither are considered basic units of life (Lederberg 1952, 2003; Roossinck 2012).

The original symbiosis concept does not specify the nature of the living arrangement that exists between distinct organisms. The exact nature of the symbiotic relation between distinct individuals can be characterized further as neutralism (when the symbiosis neither harms nor benefits either of the partners), commensalism (when one partner benefits from the symbiosis and the other is unaffected), mutualism (when both partners benefit), parasitism (when one organism benefits and the other is harmed), amensalism (where one organism is harmed or killed and the other is unaffected), and synnecrosis (where both partners are harmed or killed by the symbiotic association) (Table 1).

Symbiotic interactions are numerous and diverse. One organism can simultaneously entertain different kinds of symbioses with a variety of organisms. So far, scholars have not been able to delineate a limit on how many organisms can simultaneously engage in a symbiotic association. What is becoming increasingly clear though, is that many commensal and mutual symbiotic associations are often necessary to obtain and maintain normal development, successful survival, and reproduction. Because symbiosis impacts adaptation, reproduction, and fitness, symbiosis can affect speciation and, in cases such as synnecrosis or amensalism, extinction (Brucker and Bordenstein 2012; Gontier forthcoming; Pound 1893; Schneider 1897).

Table 1 Possible symbiotic associations

\begin{tabular}{l|l|l}
\hline Types of symbioses & Effects on species 1 & Effects on species 2 \\
\hline Neutralism & 0 & 0 \\
\hline Commensalism & + & 0 \\
\hline Amensalism & - & 0 \\
\hline Mutualism & + & + \\
\hline Parasitism & + & - \\
\hline Synnecrosis & - & - \\
\hline
\end{tabular}

+ beneficial; - harmful; 0 indifferent 
Commensal, mutual, parasitic, or amensal symbiotic associations with microorganisms also impact organismal health, which is something we return to in the part on infectious heredity.

The effects of symbiotic associations extend the organisms that engage in the living arrangement because symbiosis can significantly alter biotic and abiotic ecological systems from the lowest to the highest hierarchical level. The evolution of photosynthesizing cyanobacteria, for example, which is estimated to have occurred between 2.7 and 2.4 billion years ago, is known to have severely impacted the earth's atmosphere and climate (Carrapiço 2006; Dole 1965; Flannery and Walter 2012; Holland 2006; Melezhik 2006; Pentecost and Franke 2010; Robert et al. 2005). The origin of photosynthetic life forms (organisms that produce oxygen as a waste product), led to the great oxygenation event which commenced somewhat 2.4 billion years ago. The transition from a reducing atmosphere to an oxygen-rich atmosphere led to the oxygen catastrophe, i.e., the first major extinction event where obligate anaerobe life forms that evolved in the Hadean and Archean became severely threatened. The great oxygenation event was a precondition for oxygen-respiring life forms to evolve, and it triggered the Huronian glaciation (the first ice age). These environmental changes were also one of the triggers for the evolution of symbiogenesis out of permanent symbiosis, where, as an adaptive environmental response, various life forms increased in size and sought permanent shelter in one another to find protection against the devastating environmental conditions.

In this volume, Zook provides us with a current state of the art as well as a new definition of symbiosis, Carrapiço reviews the history of symbiosis research, and Faria and Sucena exemplify how endosymbiosis can induce rapid speciation.

\subsection{Symbiogenesis}

Symbiogenesis is an evolutionary mechanism that occurs through "long-term hereditary symbiosis" (Margulis and Dolan 2000: 157). The fact that symbiotic associations can become hereditary was first acknowledged by von Faber (1912) who attested that bacteria found inside tropical plants engaged in a form of "erbliche Zusammenleben." The latter term was translated as "hereditary symbiosis" by Cowles (1915) and was later adopted by scholars such as Buchner (1921, 1939), Wallin (1927) and Lederberg (1952).

The concept of symbiogenesis was first introduced by the Russians Constantin Merezhkowsky, Andrey Famintsyn, and Boris Kozo-Polyanski (Sapp 1994). By building on earlier work of Andreas Schimper, the Russians pointed out that chloroplasts, organelles found in algae and plant cells, had evolved from cyanobacteria that engaged in long-term symbioses. The permanent endosymbiosis resulted in symbiogenesis: the cyanobacteria evolved into organelles, cellular structures that permanently reside inside the cells. With the Russians, hereditary symbiosis became understood as a causal agent in the evolution of new morphological 
features, and symbiogenesis was identified as an evolutionary mechanism whereby species evolve. A symbiogenetic origin for mitochondria, which are also eukaryotic organelles, was conjectured by Paul Portier in France (who identified them as "cellular symbiotes"), and in America by Ivan Wallin who adopted the notion of hereditary symbiosis and introduced the concept of "symbionticism" (Sapp 2003).

Our modern notions on symbiogenesis come from Lynn Margulis (Sagan 1967; Margulis 1970, 1998), who from the late 1960s onwards reintroduced, systematized, and expanded these ideas into the encompassing Serial Endosymbiotic Theory (Fig. 1). SET-theory,

\begin{abstract}
... presents a theory of the origin of ... discontinuity between eukaryotic (mitosing or 'higher') and prokaryotic cells. Specifically, the mitochondria, ... and the photosynthetic plastids can all be considered to have derived from free-living cells, and the eukaryotic cell is the result of the evolution of ancient symbioses. Although these ideas are not new [Merechowsky (1910) and Minchin (1915) in Wilson (1925), Wallin (1927), Lederberg (1952), Haldane (1954), Ris and Plaut (1962)], in this paper they have been synthesized in such a way as to be consistent with recent data on the biochemistry and cytology of subcellular organelles. (Sagan 1967: 226)
\end{abstract}

Contrary to Woese (Woese et al. 1978, 1990; Woese and Fox 1977) Woese and Fox 1977) who divides life into three domains, namely Archaea, Bacteria, and Eukaryota, Margulis endorsed a 5-kingdom classification of life and understood symbiogenesis as the distinguishing feature that separates prokaryotic organisms such as Archaebacteria and Eubacteria belonging to the Monera kingdom from all eukaryotic organisms, i.e., the Protoctists or protists (for the difference see Rothschild 1989), Fungi, Animal and Plant Kingdoms (Whitaker and Margulis 1978). For Margulis (1998: 42):

symbiogenesis is the factor that distinguishes all nucleated-cell life from all bacterial life. No middle ground exists - either a group of organisms evolved by symbiogenesis or it did not. My claim is that all nucleated organisms (protoctists, plants, fungi, and animals) arose by symbiogenesis ...

SET provides a theory for the origin of the four eukaryotic kingdoms which have evolved by three symbiogenetic mergings (Fig. 1).

The first merger is still controversial among scientists and involves the origin of the eukaryotic cell. According to SET, the eukaryotic cell evolved from a permanent hereditary symbiosis between different prokaryotes, namely Archaeplasmalike archaebacteria (Thermoplasma acidophilium) and Spirochete-like eubacteria. Archaeplasma bacteria are anaerobe and fermenting microorganisms that today are classified as a genus in the Archaea domain. Spirochetes are a phylum of doublemembraned, corkscrew-shaped, mobile bacteria, today classified as belonging to the domain of Bacteria. The symbiotic merger between these distinct individuals, for Margulis, enabled the origin of the first nucleated cells, overall cell movement, and the formation of the mitotic spindle (Margulis et al. 2000, 2006).

In eukaryotic cells, the nucleated genes are organized on separate chromosomes. The mitotic spindle is a microtubule-rich organellar structure found outside the nucleus that helps in pulling apart the chromosomes during mitosis. Mitosis involves a series of complex movements of compartmentalized genes, and for 


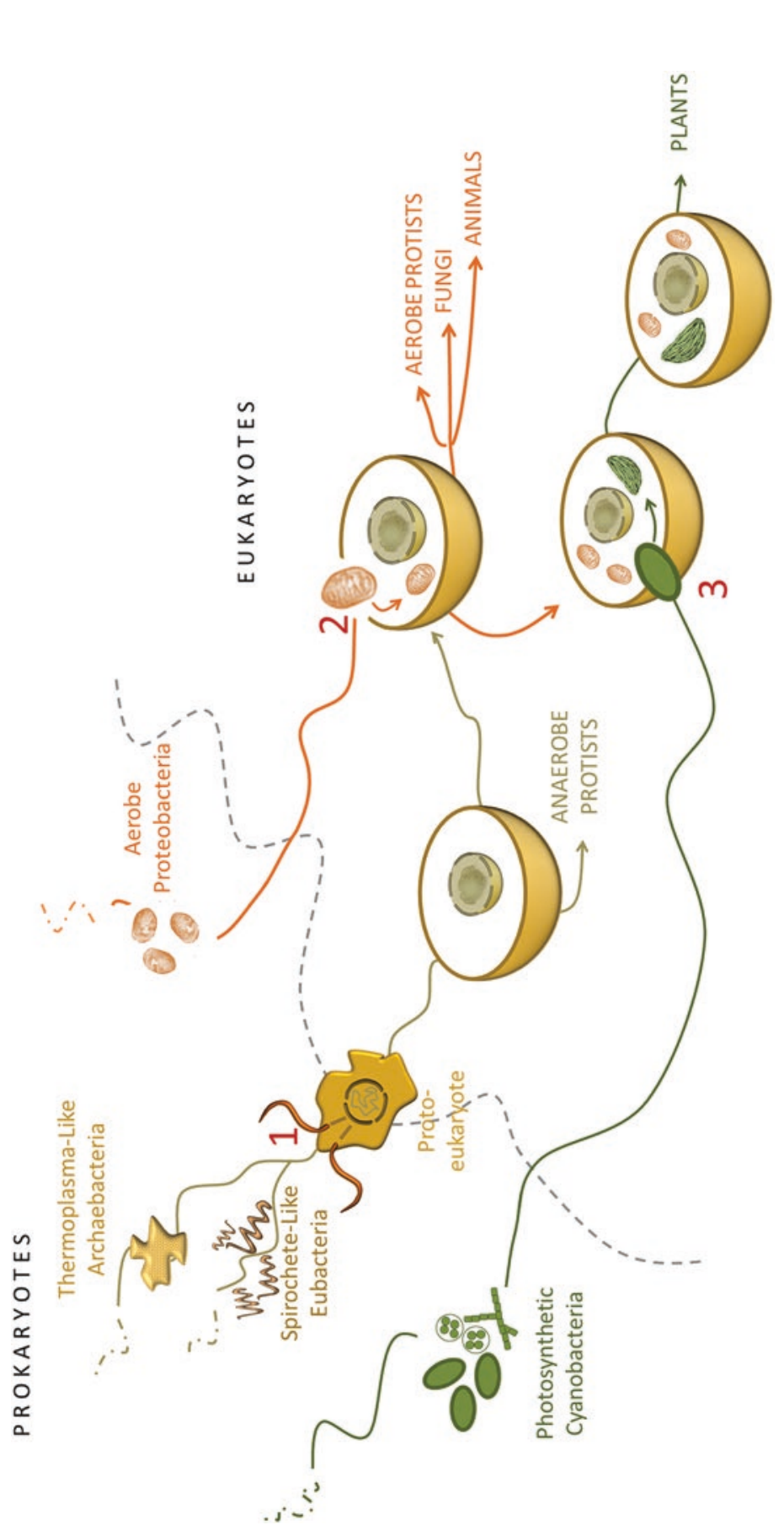

륭

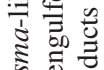

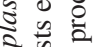

․ํㅇ

है

iิ.

可 를

혼

๘

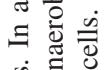

ฉ

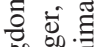

离

모 믈

융

昰卷

ठ

言离志焉

\& 0.0

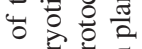

흘

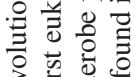

훙

\&. 苟

Ð

을 응

웡

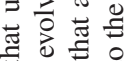

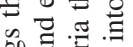

品寻

क्ञ

छ

.

는

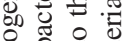

율월

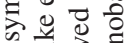

ช :

छ ฮे

ช :

ते

.

들

ปั ป

น :

- D \&

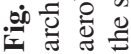


Margulis (1998: 40-43), spirochetes are what enabled this internal movement or "dance of the chromosomes." The first merger also enabled external movement, because it gave rise to undulipodia ("waving feet"), including cilia, the "tails" and "hairs" of eukaryotic cells. For that reason, the first merger is also called "motility symbiosis."

Evidence for motility symbiosis is found in the structure of centrioli, undulipodia and cilia. Centrioli make up the centrosome, i.e., the microtubules-organizing center important for mitosis. Centrosomes also lie at the formation of kinetosomes, the basal bodies wherefrom moving organelles (undulipodia and cilia) extend. Undulipodia and cilia are made up of microtubular structures that in their shaft (the axoneme) have microtubules arranged according to a $[9(2)+2]$ pattern and in their basal bodies (kinetosomes) they all have microtubules arranged according to a $[9(3)+0]$ pattern. This latter pattern is identical to the microtubular organization found in centrioli (Fig. 2), and the centrioli are responsible for the formation of the kinetosome as well as the mitotic spindle. Based upon their morphological similarity, in SET theory, centrioli, undulipodia, and cilia are conjectured to have evolved from once-free-living spirochetes because free-living spirochetes often contain cytoplasmic tubules that resemble microtubules (Margulis and Dolan 2001: 89-96).

Contrary to SET theory that explains the origin of all eukaryotic cell types as resulting from permanent symbioses between different prokaryotes, several scholars (Livingston Bell 2001; Villarreal and Witzany 2010: 699) have suggested a viral origin for the eukaryotic nucleus. In this scenario, archaea-like organisms symbiogenetically integrated double-stranded DNA virus(es) which enabled the origin of hypercyclic DNA compartmentalization. Both scenarios need not be mutually exclusive, but so far, no scholar has tried to integrate both views into an overall tripartite chronological sequence.

The second and third merger involve the origin of mitochondria and chloroplasts, two eukaryotic cell organelles. The second merger of SET theory describes the evolution of mitochondria from aerobe proteobacteria that started to entertain permanent symbiotic relations with some of the first eukaryotic beings (possibly in response to the oxygen crisis); and in a third merger, chloroplasts evolved from the intracellular incorporation by phagocytosis (eating or engulfing) of cyanobacteria. In both cases, these once-free-living bacteria were engulfed by the first eukaryotic life forms, the endosymbiosis with the intracellular guests became permanent and hereditary, and this hereditary symbiosis led to the evolution of the respective organelles. Not all cyanobacteria and proteobacteria (which both encompass large taxonomic groups) engaged in symbiosis, and to this today, both cyanobacteria and proteobacteria continue to live independently of eukaryotic organisms.

Mitochondria and chloroplasts contain their own DNA and their endosymbiogenetic, bacterial origin is today undisputed because there is proof coming from comparative molecular phylogenetics (Bonen and Doolittle 1975, 1976; Bonen et al. 1977). The DNA found in these cellular organelles still relates more closely to the free-living bacteria where they presumably evolved from than it does to the nuclear genes of the cells they belong to. 


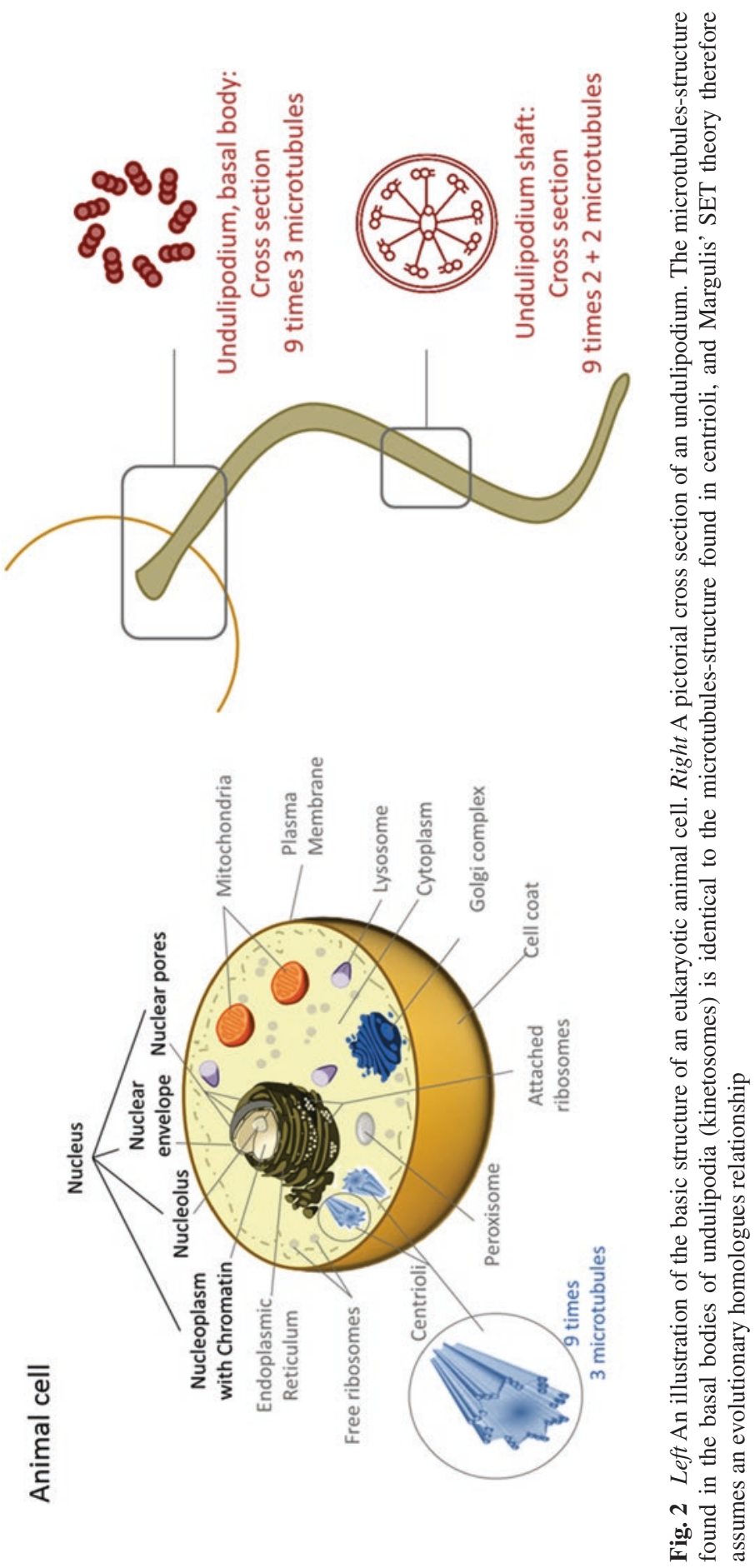


All chloroplasts thus appear to be related by common descent from cyanobacteria. Nonetheless, these plastids have been acquired repeatedly, often as primary, secondary, and tertiary endosymbiosis events. Eukaryotic organisms with chloroplasts in place and forming a primary endosymbiosis were completely engulfed by other eukaryotes where the engulfed organism, as a whole, started to function as a chloroplast. Products of this secondary endosymbiosis in turn have also been engulfed by other eukaryotes, a process called tertiary endosymbiosis (Archibald 2011, 2014). Symbiogenesis as an evolutionary mechanism therefore not merely evidences a pattern of reticulation, it also demonstrates a pattern of increased embedding, comparable to Russian dolls, though the dolls have different morphologies rather than being identical. Mitochondria, in turn, have all evolved from proteobacteria with which they still share a high genetic similarity.

Evidence is furthermore accumulating that proves that these organelles have undergone considerable gene loss after their symbiogenetic acquisition (Archibald 2014), and they have engaged in lateral gene transfer with the nuclei of eukaryotic cells, in both directions (Archibald and Richards 2010; Blanchard and Lynch 2000; Martin and Herrmann 1998). Finally, Margulis also associated SET theory with the Gaia hypothesis which was first introduced in its modern form by Lovelock (1972) and later elaborated by both authors (Lovelock and Margulis 1974).

Besides chloroplasts that are found in all plant cells, and mitochondria, found in all aerobe protist, plant, fungal and animal cells, eukaryotic cells contain many more organelles, and their evolutionary origin remains obscure. The Belgian cytologist, de Duve et al. (1974), who first discovered lysosomes (eukaryotic organelles found in animal cells and involved in housekeeping), also suggested a symbiogenetic, bacterial origin for these organelles.

In this volume, Zook elaborates upon primary, secondary, and tertiary endosymbiosis, which is especially relevant for understanding the origin of green and red algae as well as dinoflagellates (marine plankton that often combines photosynthesis with phagotrophy: the engulfment and eating of prey). And both Zook and Carrapiço explain how symbiogenesis is to be understood as an evolutionary mechanism in and of itself that complements the mechanism of natural selection. Correia and Manso provide a computational model to simulate symbiosis, symbiogenesis, and lateral gene transfer.

\subsection{Horizontal or Lateral Gene Transfer}

Lateral gene transfer is the process whereby genes are exchanged horizontally, either between distinct organisms with different genealogical histories, or between distinct genomes present in the same organism (e.g. between gene-containing organelles and the nucleus; or between the bacterial genome and plasmids residing inside the bacterial cell). In prokaryotes, lateral gene transfer occurs mainly by mechanisms of transformation, transduction, and bacterial conjugation (Fig. 3). 


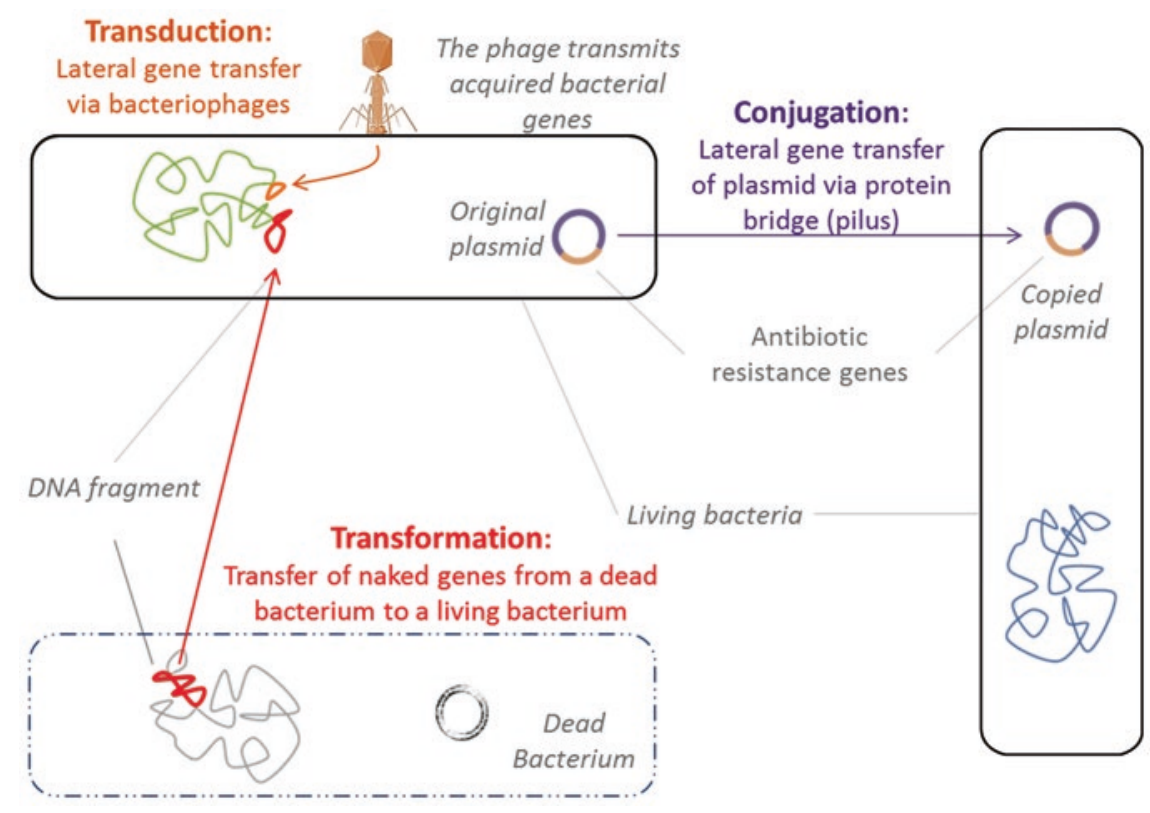

Fig. 3 Schematic of the three main mechanisms of lateral gene transfer in prokaryotes

Transformation involves the uptake of naked DNA from the surroundings, and the process was first described by Frederick Griffith and later confirmed by Oswald Avery, Colin MacLeod, and Maclyn McCarthy. Transduction was first described by Joshua Lederberg and Norton Zinder and involves the transfer of bacterial genes via bacteriophages, i.e., bacterial viruses. Bacterial conjugation, or bacterial mating as it is often called, was discovered by again Joshua Lederberg, in collaboration with Edward Tatum, and involves the transfer of plasmids.

A plasmid is an extrachromosomal (Lederberg 1952), mobile genetic element (Shapiro 1983), often made up of circular DNA. Plasmids are central agents for lateral gene transfer by means of bacterial conjugation whereby a single strand of the double-stranded plasmid is laterally transferred from a donor bacterium to a recipient. Plasmids often carry antibiotic resistance genes, and via bacterial conjugation, these resistance genes are exchanged between bacterial populations. Such "extra genes" are not necessary for the bacterium to survive, but they can nonetheless increase the bacterium's chances of survival and therefore also its fitness.

Several bacteria also contain Gene Transfer Agents (GTAs) in their genome. GTAs are bacteriophage-like elements that are horizontally exchanged (Maxmen 2010; Stanton 2007), and they present a fourth form of lateral gene transfer among bacteria.

Prokaryotes and eukaryotes alike contain "jumping genes" (McClintock 1950, 1953) or transposons. These are mobile genetic elements that can change their position in the genome and move to another location. They can switch their 
position inside the genome they belong to, or they can travel horizontally from the bacterial genome to a bacterial plasmid or vice versa, or from organellar DNA to nuclear DNA and vice versa. Retrotransposons are a subclass of transposable elements found in eukaryotes (Engels and Preston 1981; Frost et al. 2005; Kazazian et al. 1988; SanMiguel et al. 1996; Shapiro 1969; Singer 1982; Taylor 1963). Retrotransposons are alternatively known as transposons via RNA intermediates, because they move about by copying and inserting themselves via RNA intermediates. Transposons are always made up of DNA, and they cut and paste themselves into genetic sequences (Finnegan 1989).

Transposons leave gaps at the places where they cut themselves and often interrupt the gene sequence where they insert themselves, while retrotransposons enable genome growth by duplication of gene sequences, and both therefore enable "genetic transformation" (Rubin and Spradling 1982) of the organismal genome they belong to. In other words, they change the genetic make-up of organisms and are therefore key players in evolution.

Another type of mobile genetic elements are retroviruses. Retroviruses can insert their genes into the host's genome, and they can become transmitted vertically. Retroviruses furthermore resemble certain retrotransposons, making some scholars believe they are evolutionary related (Flavell 1981; Nelson and Hooley 2004; Ryan 2009; Temin 1980).

Scientists are currently mapping the various mobile genetic elements there exist in order to find recurring structures, elements, patterns, and mechanisms whereby these elements are transmitted. These efforts are designated as the mobilome projects (Frost et al. 2005; Siefert 2009).

The abundant occurance of lateral gene transfer in all three domains of life has only been recognized in recent years. Molecular phylogenetic reconstructions (Doolittle 2000; Gogarten 2000; Bapteste 2014; Sapp 2009) now provide conclusive evidence for "alien" or exogenous DNA uptake, which has greatly contributed to the general academic reception and recognition of the phenomena. Nonetheless, the existence of jumping genes and many of the mobile genetic elements, as well as the basic mechanisms whereby prokaryotes exchange genetic material horizontally, were already identified in the beginning of the twentieth century, mostly under artificial laboratory conditions.

In this volume, Summers provides a history of plasmids, and Dionisio et al. provide a symbiotic account of non-transferrable plasmids. Gontier sketches the discoveries of lateral gene transfer mechanisms in history and relates it to current epistemic debates on the "web" versus "tree" of life.

\subsection{Hybridization}

Originally, the neo-Darwinian framework mainly provided a theory on animal evolution, and both natural and sexual selection theories rely heavily on eukaryotic reproduction systems such as sex that enable the differential vertical 
descent of (mutated) genes over generations through time (Gontier forthcoming). Prokaryotes, however, reproduce by division and also many plants and flowers reproduce asexually by division or "cloning." When plants and flowers do reproduce sexually, they do so by means of cross-fertilization (where the gametes of sexually different individuals belonging to the same species join-similar to animal sex), self-fertilization (many flowers have both male and female sex cells that recombine during reproduction within the same, bisexual individual), pollination (the transfer of pollen from anther to stigma often mediated by insect species such as wasps and bees that live in symbiotic association), or hybridization (LópezCaamaI and Tovar-Sánchez 2014).

Hybridization occurs when two genetically distinct individuals (that in turn can belong to different subspecies, species, genera, and even families) reproduce offspring. The offspring can be infertile, but most of the time they are fertile, and the hybrid can reproduce either with its parental lineages (backcrossing or introgression) or only with similar hybrids. In both cases, hybridization can lead to the introduction of novel features as well as new species altogether (Arnold 1997, 2004, 2006; Harrison 1990; Mallet 2005, 2007; Rieseberg 1995, 2001).

In many ways, the Modern Synthesis has prohibited hybridization to become recognized as an evolutionary mechanism that can, and often does, induce speciation. Hybridization poses a problem for the neo-Darwinian paradigm. Mayr's (1942) biological species concept, for example, defines species based upon sexual compatibility and geographical accessibility. Per definition, individuals that can produce fertile offspring belong to the same species and such a definition logically excludes speciation to occur because of sexual exchange between individuals belonging to distinct species. But this is exactly what happens during hybridization, when individuals of distinct species mate and produce offspring.

Hybridization of animals was already recognized in ancient societies. Mules, for example, were deliberately bred. The word "mule" stems from "mulato" or "half-breed," and it was also used to designate humans with multiple-ethnic origins from the Middle Ages onwards. At the time, scholars falsely divided the human species into separate races. Colonization led to many mixed marriages and "bastard children," leading naturalists and clergyman of the seventeenth, eighteenth, and nineteenth century to speculate on the long-term consequences of mixing. John Ray, for example, in a paper presented at the Royal Society of London in 1684, argued that hybridization violates the divine order in the world for God had created the species in a fixed form, and he speculated that hybridization would have devastating influences on the "pure breeds" (Kingsbury 2009). In short, debates on the consequences of hybridization ran high in pre-evolutionary societies and are very much comparable to current debates on the long-term consequences of genetic engineering that artificially combines hybridization with endosymbiosis and LGT techniques.

The mechanisms of pollination in flowering plants and the recognition that also plants have sexes and reproductive organs was only recognized in 1694 , by the German scholar Camerarius or Rudolph Jakob Camerer (Roberts 1929; Zirkle 1934, 1935). Thomas Fairchild in London and Josef Gottlieb Kölreuter in Germany would 
attempt to produce deliberate crosses of various plant species (López-Caamal and Tovar-Sánchez 2014). In 1720, Fairchild presented to the British academic community what would become known as "Fairchild's mule," a deliberate cross he produced in 1717 between two plant species belonging to the Dianthus genus, known as Dianthus barbatus and Dianthus caryophyllus. Kölreuter mixed various species of tobacco plants in the 1760s, but many of those turned out sterile, making Kölreuter agree with Ray and conclude that hybridization was against divine creation and that it would eventually lead to sterility in the offspring of all crosses.

Carolus von Linnée or Linnaeus (1753) also applied the incoming knowledge of the existence of sexual organs in plants. In his double-volumed work on the taxonomy of plants, he provided the first systematic classification of round and about 9000 different plant species.

Linnaeus classified plants based upon a sexual system which he dubbed "Clavis Systematis Sexualis," a system later incorporated in the 10th edition of his Systemae Naturae. Plants were considered to undergo "public" or "clandestine marriages," and plant species were further differentiated based upon whether or not the marriage between the sexual partners lasted in time, whether they had different means to engage in sexual reproduction (e.g., by pollination, self-fertilization), and whether or not the species were monogamous or endorsed promiscuous relations with multiple partners. Though his system made use of logical and binary oppositions, and thus remained based upon artificial classifications, he first attempted to classify the naturally occurring hybrids of different plant species and he also came to recognize that hybridization challenges the idea that species are fixed entities that undergo no significant change through time.

The incoming results on the rather "promiscuous" intercourse and "marriages" between various plant species thus first facilitated evolutionary thinking. For Christian Konrad Sprengel, who would later inspire Darwin, hybridization led him to understand that species are not fixed but in constant flux, and also Karl Friedrich von Gärtner, who was able to produce fertile crosses, recognized the potential hybridization had for agriculture and the production of more nutritional crops (for reviews, see Kingsbury 2009; Camaal and Sanchez 2014). Darwin himself endorsed ideas on genetic blending and recognized hybridization to occur, but nonetheless, the neo-Darwinians focused on genetic recombination as it occurs by cross-fertilization between distinct sexual members of the same species.

At the turn of the twentieth century, Erich von Tschermak von Seyssenegg (one of the rediscovers of Mendel) in Austria also studied hybridization, as did the Danish scholar Øjvind Winge who was able to produce stable hybrids, and the Swedish geneticist Arne Müntzing who discovered chromosomal recombinations (Camaal and Sanchez 2014). Nonetheless, plant hybridization and introgression (the backcrossing of diverging species with the parental stock) (Fig. 4) was especially brought to the attention of the modern scientific evolutionary community by Anderson (1949) and Stebbins.

Stebbins was responsible for integrating plant studies into the Modern Synthesis by introducing the first "botanical synthesis" (Smocovitis 1997, Smocovitis and Ayala 2000) in his major 1950 work on "Variation and Evolution in Plants" (Stebbins 1950). 

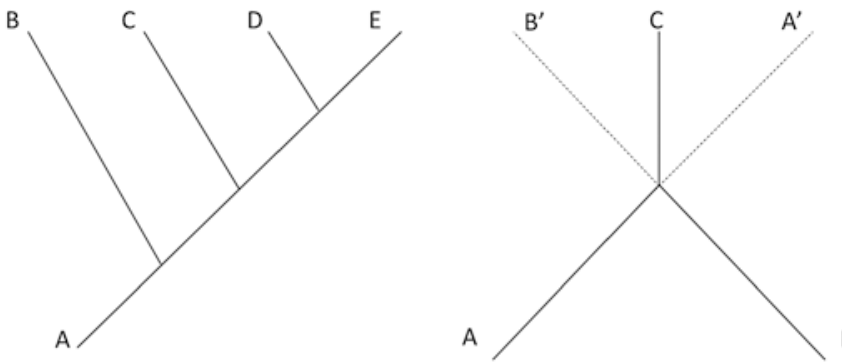

B
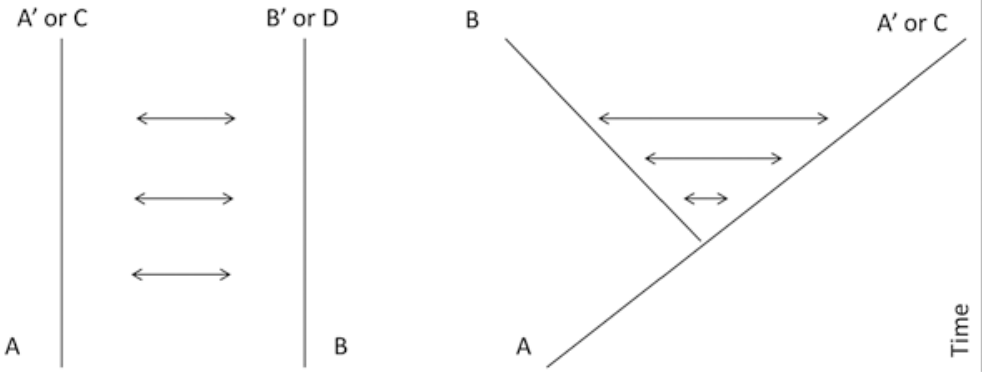

Fig. 4 Different modes of speciation, Top left Speciation by natural selection and drift: Species $B, C, D$ evolve by splitting off from species $A$ (cladenogenesis), while Species $A$ gradually evolves into a new species $E$ (anagenesis). Top right Speciation by hybridization: Members of species $A$ and $B$ cross and form a new species $C$, while species $A$ and $B$ either seize to exist due to the crossings or continue to evolve independently. Bottom left Speciation by symbiosis, symbiogenesis, lateral gene transfer, or hybridization: species $A$ and $B$ maintain symbiotic relations, acquire symbionts, or exchange genes horizontally, or they regularly hybridize, while they remain distinct species. Species $A^{\prime}$ and $B^{\prime}$ are nonetheless genetically, morphologically, or behaviorally altered by the various crossings, transfers and symbiotic associations in time, possibly up to the point that they evolved into new species (species $C$ and $D$ ). Bottom right Divergence by gene flow or introgression: During its divergence from species $A$, species $B$ either regularly backcrosses with its parental species (introgression), or exchanges genes laterally (directly or via symbiosis), thereby causing both species to diverge in time. This leads to the evolution of a new species $B$, and also the parental species is genetically altered (species $A^{\prime}$ ), possibly up to the point that it evolved into a new species (species $C$ )

Stebbins began his career by studying the Crepis genus, a genus of flowering plants popularly known as Hawks Beard that contains around 200 different species and that belong to the Cichoriaea tribe that also includes common lettuce, chicory, and other plants. Babcock and Stebbins (1938) discovered that many Crepis species regularly hybridize, that hybridization leads to polyploidy (chromosome doubling), and they pointed out that hybridization maximizes both variation and the potential to occupy diverse ecological niches. For Stebbins (1940), polyploidy in particular was important to understand the evolution of new plant genera. With 
Stebbins, Crespis species soon became what Drosophila provides for geneticists, Escherichia coli for bacteriologists, and Wolbachia for scholars studying lateral gene transfer and symbiosis: a model organism.

By invitation of Ernst Mayr and Theodosius Dobzhansky, both major founders of the Modern Synthesis, Stebbins (1959) combined hybridization with natural selection theory and theoretical population genetics, systematics, and taxonomy. With the 1959 book, he launched the new field of evolutionary plant biology and he dedicated full chapters to hybridization and polyploidy which he understood to be targets of natural selection.

Anderson (1949), who coined the term introgression, pointed out the creative role hybridization can play because hybrids may backcross with their parental species, thereby increasing genetic diversity, adaptation, and fitness of both populations. Anderson was also a member of the Society for Evolution that gave way to the foundation of the Modern Synthesis (Gontier forthcoming; Smocovitis 1997). Together with Stebbins, he emphasized that hybridization plays a significant role in evolution because hybridization introduces new variation and enables a wider occupancy of ecological space (Anderson and Stebbins 1954).

Stebbins and Anderson's ideas on hybridization as adaptive for individual organisms and long-term beneficial for species are today proven by numerous scholars (e.g., Arnold 2004, 2006; Harrison 1990; Mallet 2005, 2007; Riesenberg 1995, 2001), who furthermore add that hybridization facilitates speciation and extinction, as well as provides a means to enter the genome of foreign species (Mallet 2005, 2007).

Because plant hybridization and introgression is well-documented and wellrecognized to occur, in this volume, Arnold et al. focus on animal hybridization and introgression, or as the authors prefer to call it, "divergence with gene flow", in mammalian lineages.

\subsection{Infectious Heredity in Health, Disease and Evolution}

Many diseases are caused by the body's own (mutated) genes (e.g., following radiation), or by the malfunctioning of the individual's own metabolism and autoimmune system (e.g., systemic, auto-immune deficiencies), but the majority of diseases are caused by infectious agents that an organism haphazardly acquires during its lifetime. Infections can cause abnormal growth associated with diseases such as cancer, or benign but nonetheless obstructive tumor formation.

All three domains of life are prone to viral infections, or "viral colonization" as Villarreal calls it (Villareal and Defilipps 2000; Villarreal and Witzany 2010). There are around 50 known double-stranded, and two single-stranded DNA viruses that infect Archaea (Pietilä et al. 2014), bacteria are vulnerable to infections by bacteriophages (bacterial viruses), and eukaryotes can become infected by numerous DNA and RNA viruses as well as bacteria, fungi, worms, and small protozoan organisms. 
In multicellular organisms, parasitic bacteria such as pneumococci, for example, enter their eukaryotic host and start multiplying inside the organism. They can block vital airways such as the lungs which can lead to respiratory problems; or they can start competing with the body's own cells for resources, thereby inducing cell mortality in their host.

To enable the formation of new viruses, viruses make use of the host metabolism and upon release, they kill the host cell. Many viruses can also copy their genetic material into the genome of the host. Endogenous retroviruses or ERVs (Gifford and Tristem 2003; Löwer et al. 1996; Ryan 2009) are viruses that upon infection can horizontally insert their genetic material into their host genome. ERVs resemble retrotransposable elements (Nelson and Hooley 2004), and they are often classified as a subtype of the latter. ERVs make use of the genetic apparatus of the somatic cells, but they can also integrate in the genomes of the sex cells and nestle inside the germ line. Once they become part of the germ line, the genes become the subject of vertical transmission where they are passed on to future generations in a Mendelian fashion. It is now well established that the genomes of mammals contain bits and pieces of these viruses in regions that were previously designated as "junk DNA." The genomes that acquire retroviral genes, however, not merely serve as containers for the latter. On the contrary, the acquired retroviral genes often play crucial functional roles in developmental pathways. It has been proven that endogenous retroviruses played a significant role in the formation of the female placenta (Knerr et al. 2002; Sugimoto and Schust 2009). Evidence furthermore suggests that our human ancestors caught endogenous retroviruses from Neanderthals (Marchi et al. 2013). At least theoretically, it is likely that Neanderthals reciprocally caught some of our infectious diseases, which might have eventually contributed to their decline.

Our specific human history is also filled with pandemics such as the plague, cholera, tuberculosis, Ebola, SARS, HIV, and child diseases such as the measles or rubella. These diseases often spread nation- and worldwide. Travel induced by war, colonization, or commerce enables the spread via various modes of human contact and as such these epidemics and pandemics can influence human life history as well as human evolution (Gontier 2006, 2007). In this regard, Ryan (2005, 2006; 2009) has introduced the term plague culling. When infectious diseases populate biological groups, species, or higher taxa, or when they make their way into the germ line, then over evolutionary time, they can introduce new features, cause bottle necks, or induce speciation events, and as such play a creative role in evolution.

Research on neurodegenerative diseases has led to the identification of prions by Prusiner (1982, 1991). Prions are infectious proteins that underlie mammalian neurodegenerative diseases such as Creutzfeldt-Jakob disease in humans and Bovine Spongiform Encephalopathy (BSE) or mad cow disease in bovines; as well Kuru in humans, and Scrapie in sheep. Creutzfeldt-Jacob disease and BSE are also related in etiology and caused by similar prions. Prions are proteins that undergo post-translational, epigenetic changes in their three-dimensional folding structure. Thus, after the genetic code is transcribed and translated into proteins, the protein 
that makes up the prion undergoes further, non-genetically encoded alterations in form. What exactly causes the proteins to change form is still uncertain, but Spiroplasma bacteria have been implicated (Bastian et al. 2007). Once the proteins flip into prions and take on the altered morphological form, these prions can bind to the regular proteins and make them change form as well. The prion-induced disease is able to spread across the brain and causes neurodegenerative, spongiform diseases where the brain starts to shrink in size and morphologically starts to resemble a sponge.

Prions cannot only become spread intraspecifically, they can also spread interspecifically by horizontal transmission. When humans, for example, eat with BSEinfected cow meat, it can induce the development of Creutzfeldt-Jacob disease which is exactly what happened in the early 2000s, in the UK and other European countries (see, e.g., the European Parliament and Council Regulation (EC) No 999/2001 on the "TSE-regulation" or the laws and decrees enacted against the spread of Transmissible Spongiform Encephalopathies at http://ec.europa.eu/food/ food/biosafety/tse_bse/legisl_en.htm).

In sum, viruses, bacteriophages, bacteria, fungi, worms, protozoa, and also prions (Fig. 5) can function as pathogens or infectious agents. They are horizontally acquired, and they can become intra- and interspecifically transmitted in both vertical and horizontal fashion, via the germ line, or via the blood, milk, mucus, or other bodily fluids; they are ingested via food resources; or caught via inhaling infected air. Infectious agents can also become horizontally transmitted via vectors, i.e., symbiotic organisms that themselves carry microorganisms which are transmitted from the symbiont to the host.

All infectious agents are also symbionts, and not all infectious agents are pathogens that cause disease. Our gastro-intestinal tract, for example, provides an

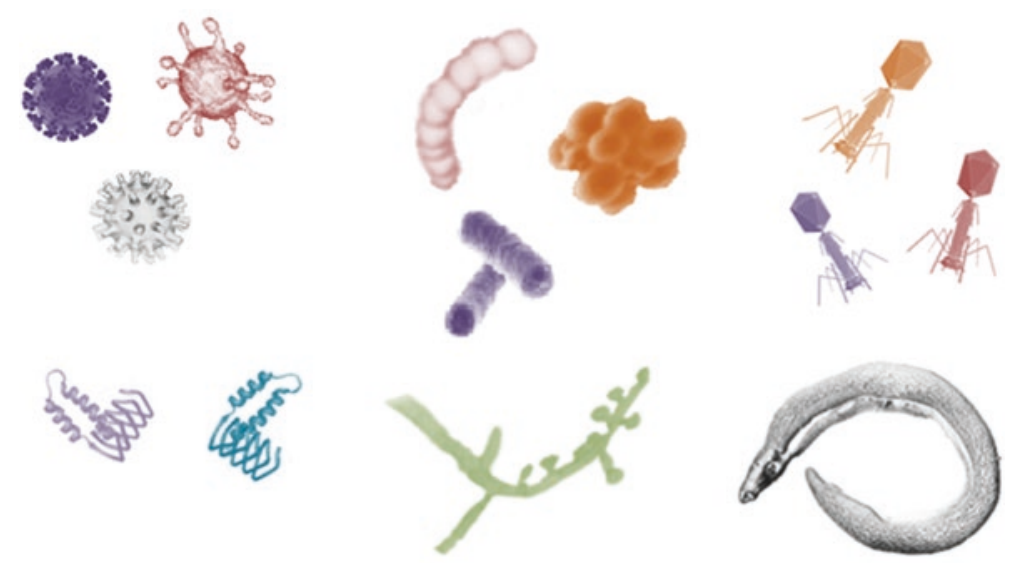

Fig. 5 Examples of infectious agents (not to scale). From left to right and top to bottom: viruses, bacteria, bacteriophages, prions (infectious proteins), fungi, worms. The prions are based on https://microbewiki.kenyon.edu/index.php/File:R7_prion.jpg 
oxygen-low environment, and is therefore a suitable niche for the anaerobe organisms that first evolved under a reduced atmosphere. Over millions of years, these anaerobes have found shelter in multicellular organisms, and in return, the symbionts often provide the host with traits and biochemical substances that the host can neither produce nor establish on its own. Anaerobe gut flora is known to contribute to digestion of certain food substances, they help build the colon walls, and they often protect their host against infections with less beneficial microbes (Backhed et al. 2005; Turnbaugh et al. 2007, 2009; Ley et al. 2006). Current studies are even pointing towards the various compositions of microbiomes to explain body weight, sexual attraction, stress responses, temperament, and personality (Foster and McVey Neufeld 2013; Ley 2010; Bravo et al. 2012; Venu et al. 2014).

Multicellular, eukaryotic organisms have evolved complex anatomical forms and their various bodily organs and systems are populated by numerous microorganisms with which the eukaryotic hosts entertain symbiotic relationships. Scholars are increasingly demonstrating that besides parasitic symbiotic associations, also mutual and commensal associations between infectious agents and their hosts contribute to acquiring and maintaining normal development and overall health. Scholars are currently engaged in mapping the various microbiota, i.e., protozoan, microbial, and viral communities, that symbiotically live inside or onside eukaryotic organisms. These endeavors are known as microbiome and viriome projects and include the Human Microbiome Project that was launched by the American National Institute of Health (The NIH HMP Working Group 2009; the official website of the Human Microbiome Project can be found at http://www.hm pdacc.org/).

The complex symbiotic associations with the microbiomes, viriomes, and other microbiota furthermore need to be understood in terms of coevolution and lateral gene transfer (Dunning Hotopp et al. 2007). The host often provides environmental and ecological conditions suitable for microbial or viral growth, and (parasitic) symbionts can exchange genes laterally with their host, leading to altered genetic codes and altered metabolism.

Lederberg first coined the terms "microbiota" and "microbiome" in the early twenty-first century, to delineate "the ecological community of commensal, symbiotic, and pathogenic microorganisms that literally share our body space and have been all but ignored as determinants of health and disease" (Lederberg and McCay 2001). Earlier in time, and to emphasize the association there exists between infectious agents and symbiosis, he popularized concepts such as "hereditary symbiosis" (Lederberg 1952), and "infective transmission" (Lederberg 1998: 1) to delineate "DNA-mediated transformation, or virus-mediated transduction" (Lederberg and Lederberg 1956), as well as "infective heredity"- a concept first used by one of his collaborators, Zinder (1953), to describe Lederberg's work on bacterial transduction and conjugation. Writing in a time before "lateral gene transfer" as a notion was coined, he associated both infectious agents as well as the various means of prokaryotic horizontal gene exchange with symbiosis theory. For Lederberg (2003: 287), "We should think of each host and its parasites as a superorganism with the respective genomes yoked into a chimera of sorts." This 
introduces a "sociological development," or, in other words, a coevolutionary and social epistemic dimension to research on chimeric organisms.

In short, infectious heredity deals broadly with the horizontal acquisition of infectious agents, as well as the impact infectious agents have on health and disease of their host, both ontogenetically and phylogenetically. Classically, infection is understood as an ontogenetically acquired trait. Because the founders of the Modern Synthesis adhered to the Weismann barrier that rejected any type of Lamarckian inheritance and evolution, ontogeny was not considered to influence phylogeny. Research today on the contrary demonstrates that ontogenetically acquired infectious agents can most certainly influence phylogeny.

Infectious heredity therefore links the biomedical sciences with the evolutionary and ecological sciences. The acknowledgment that disease and health is induced by microorganisms was first put forward in the bacteriological and biomedical sciences when scholars like Joseph Lister in Great Britain, Louis Pasteur in France, and Robert Koch in Germany advanced the germ theory of disease (for reviews, see Sapp 1994, 2003, and for a timeline, see Campbell's 2007-2015 Germ Theory Calendar at http://germtheorycalendar.com/). Disease, in turn, became correlated to research on immunity and medicinal therapies by British scholars such as Edward Jenner and Alexander Fleming, the Russian zoologist Ilya Mechnikov, and the German scholars Paul Ehrlich and Emil von Behring (for reviews, see Gaudillière and Löwly 2001).

As early as 1949, J.B.S. Haldane, one of the population geneticists, linked the advances in bacteriology, microbiology, and the overall biomedical sciences, with evolutionary theory in an article on "Disease and Evolution" wherein he discussed various infectious diseases as agents of natural selection (Lederberg 1999). Diseases like malaria, for example, which is caused by parasitic protozoans, alter the successful survival rates of infected individuals, and certain hemoglobin disorders in turn protect against malaria.

For Haldane (1949), infectious agents can be understood as a medium through which natural selection becomes expressed. But as said, the relation between organismal diseases and the infectious agents that cause them additionally needs to be understood in terms of coevolution, symbiosis, and lateral gene transfer. Many bacteria and viruses "know" how to infect organisms, and many organisms "know" how to fight against or collaborate with the infectious agents. In other words, over the course of evolutionary history, infectious agents and their hosts have coevolved behavioral and biochemical repertoires to recognize and respond to one another. Many possess the biochemical "keys" of our bodies" "locks," and our bodies have evolved intricate immune responses that enable the identification, limitation, and even eradication of unwanted foreign agents, as well as means to recognize and use beneficial traits provided by these foreign bodies. Reticulate evolution is therefore pivotal in understanding the epidemiology of infectious disease as well as immunity.

In this volume, examples of infectious heredity, microbiome and viriome studies are discussed by Souto Maior, Weyrich, Zook, Arnold, and Gontier. 


\section{Introduction to the Chapters}

Authors in this volume provide a state of the art on current data and theory. They exemplify the mechanisms and processes by reviewing case studies of reticulate evolution as they occur in various ranks of life; by delineating the historical context of discovery wherein reticulate evolutionary mechanisms were first recognized to occur; and by explaining how reticulate evolution challenges some of the classic tenets of the standard evolutionary, neo-Darwinian paradigm.

Douglas Zook, the decade-long former president of the International Symbiosis Society (http://iss-symbiosis.org/) and inheritor Lynn Margulis' first course on symbiosis that she developed at Boston University, provides a current state of the art of symbiosis research. He provides a new definition of symbiosis as "the acquisition of an organism(s) by another unlike organism(s), and through subsequent long-term integration, new structures, and metabolism(s) emerge."

In his chapter "Symbiosis: Evolution's Co-Author," the author takes on an overall ecological approach and details how the biosphere (the global ecosystem that encompasses the habitable zones of life) is the outgrowth of intimate symbiotic interactions between living organisms and the abiotic environment. Organisms have from the very beginning and continuing over billions of years played crucial roles in the evolution of the earth's atmosphere and its biomes via processes of biomineralization, lithification (the formation of rocks), and by aiding and sustaining crucial biochemical cycles such as the nitrogen, oxygen, and carbon cycle.

From stromatolites onwards, Zook reconstructs life's early origins and explains how primary, secondary, and tertiary symbiosis events have molded early eukaryotic life. The author explains why concepts such as "mutualism," "parasitism," and "commensalism" are outdated. The concepts imply a "compartmentalization," while Zook understands symbiosis as evolution's coauthor. Both symbiosis and natural selection are the primary mechanisms whereby life's immense biodiversity evolves, and he explains why symbiosis and natural selection are not mutually exclusive concepts.

The author adopts Margulis' "holobiont" concept that designates the new entity that forms as a result of a symbiotic association as a new unit of evolution. The holobiont concept also plays a crucial role in the Rosenberg's Hologenome theory that explains how holobionts are new units of selection, and Zook details how holobiont selection results in rapid adaptation and increased fitness.

Zook ends his chapter with extracts from an unreleased video interview he conducted with Lynn Margulis on how she understood the relation between the standard neo-Darwinian paradigm and the evolutionary symbiogenetic view of life.

In his chapter Can We Understand Evolution Without Symbiogenesis?, Francisco Carrapiço, one of the former secretaries of the International Symbiosis Society, understands symbiogenesis as an evolutionary mechanism crucial for understanding biodiversity as well as speciation events.

Carrapiço shares his truly encyclopedic knowledge on the rich history that precedes symbiosis and symbiogenesis research, and reviews when concepts 
such as "consortia," “commensalism," "parasitism," "mutualism," "symbiosis," and "symbiogenesis" were first introduced in time as well as how they got redefined over the ages. He lines up numerous pioneering scholars, including Simon Schwendener, Heinrich Anton de Bary, Pierre-Joseph Van Beneden, Albert Bernhard Frank, Andreas Schimper, Constantin Merezhkowsky, Andrey Famintsyn, Hermann Reinheimer, Paul Portier, Ivan Wallin, Boris KozoPolyansky, Lynn Margulis and many many others.

Carrapiço systematically demonstrates the difficult epistemic relations there have been between symbiologists, Darwinians, and neo-Darwinians, causing symbiosis research to have developed parallel and mostly outside the standard evolutionary paradigm. The malreception of symbiosis theory by neo-Darwinian scholars is explained as resulting from different notions both paradigms entertain on the nature of the organism, species-specificity, cooperation and interaction, and the overall role ecology plays in understanding the evolution of life. The author tracks the rise of these ideas and situates them in opposing sociopolitical ideologies of the nineteenth century.

Carrapiço ends by providing guidelines on how the evolutionary paradigm can be re-conceptualized to include the important results brought forth by research on symbiosis and symbiogenesis, and the author avers for a fuller and richer understanding of the evolution of life. Symbiosis leads to "synergies" and enables the evolution of "consortia" that can be characterized as "symbiogenic superorganisms," which the author defines as "new entities or consortia formed by the integration of individual organisms, that possess characteristics that go beyond the sum of the individual properties of each element of the association, resulting in the development of new attributes and capacities as an integrated whole." He exemplifies the concept by reviewing his own work on Azolla, an aquatic fern that entertains symbiotic relations with the microorganisms that inhabit its leaf cavities.

(Endo)symbiosis is not a phenomenon confined to the evolution of organismal cell types associated with the four eukaryotic kingdoms. Rather, symbiologists agree that symbiosis continues to impact speciation. Speciation events, however, are rarely witnessed in nature, and neo-Darwinian scholars or symbiologists alike therefore have to combine observational knowledge with theory to explain how either natural selection or symbiosis, or both, can enable speciation. Symbiologists are rapidly catching up in providing new species concepts as well as theoretical scenarios on how symbiosis can lead to speciation.

The evolutionary-developmental biologists Vitor Faria and Élio Sucena detail how endosymbiosis influences and facilitates speciation of both hosts and symbionts. They explain how in particular intracellular coevolution between facultative endobacteria and their insect hosts can contribute to rapid phenotypic change and speciation of the host's progeny. In their chapter Novel Endosymbioses as a Catalyst of Fast Speciation, the authors provide a five-step scenario for the appearance of novel host lineages. Facultative bacterial endosymbionts of eukaryotic organisms are not only transmitted horizontally, they are often transmitted vertically among members of the host species. As such, they become a defining feature of the host lineage's phenotype, and they impact the fitness of their host. 
A prototypical example is Wolbachia, a genus of bacteria that entertains parasitic and mutual symbiotic associations with many insect species. Wolbachia is often vertically transmitted via the female eggs and impacts the reproductive success of both the males and females of the host insect, by disabling or enabling sexual compatibility. Faria and Sucena detail how endosymbionts like Wolbachia either impact "directional" or "disruptive selection" of their host among its conspecifics. In disruptive selection, the host's possibility to mate with its conspecifics is reduced by the presence of the endosymbiont; in directional selection, the host's ability to mate with conspecifics is increased by the presence of the endosymbiont. In both cases, the host's symbionts introduce barriers that facilitate rapid speciation by symbiosis.

Besides Wolbachia, Faria and Sucena exemplify their proposal for how speciation-by-endosymbiosis possibly occurs with numerous real-life case studies on coevolution between host and endosymbiont, fitness impacts of facultative endosymbionts, horizontal and vertical transmission of symbionts between hosts, and endosymbiont-induced phenotypic and genotypic novelties.

In the chapter on Historical and Epistemological Perspectives on What Lateral Gene Transfer Mechanisms Contribute to our Understanding of Evolution, Nathalie Gontier first reviews how lateral gene transfer has been brought to the attention of the larger academic community by results coming in from molecular phylogenetics. In the beginning of the 1990s, species-genome sequencing techniques as well as ribosomal RNA comparisons of various taxa led to the introduction of Carl Woese' three-domain classification of life. Such research also made it obvious that lateral gene transfer and symbioses occur abundantly, and scholars such as Gogarten (2000), Doolittle (2000) and Bapteste et al. (2005), among others, subsequently started to question the standard neo-Darwinian tree of life iconographies. The scholars introduced new metaphors, such as the "web of life" and "net of life" metaphor, which in turn upset neo-Darwinians such as Richard Dawkins, Jerry Coyne, and Daniel Dennett. Polemic debates followed in various journals and media. Gontier reviews these polemics and places them in historical and epistemological context.

In the second part of her chapter, she reviews the basic mechanisms according to which horizontal gene transfer occurs in both pro- and eukaryotes. Gontier traces the identification of bacterial transformation, transduction, and bacterial conjugation to pre-synthetic times where discoveries made by Frederick Griffith, Oswald Avery, Colin MacLeod, Maclyn McCarty, Norton Zinder, Joshua Lederberg, Edward Tatum, Barbara McClintock, François Jacob, and many others improved knowledge on bacteriology, immunology, and disease. She investigates why these phenomena were long considered biomedical peculiarities rather than genuine evolutionary mechanisms relevant to understanding the evolution of life.

That it is beyond reasonable doubt that horizontal gene transfer occurs abundantly, but many of the mechanisms by which genes are transferred between eukaryotic species remain obscure. It is becoming increasingly obvious though that symbioses, symbiogenesis, and hybridization act as facilitators of lateral gene transfer, and Gontier investigates how scholars today are trying to identify 
recurring patterns and mechanisms. Along the way, she identifies where and how the incoming results conflict with specific tenets put forward by the founders of the Modern Synthesis.

In the chapter Plasmids: Histories of a Concept, the historian of science and molecular biologist William C. Summers provides the context of discovery of plasmids and reviews how definitions of plasmids and associated concepts such a episomes have changed over the last decennia.

It has taken biologists some time to determine what the exact nature of hereditary particles is, and where such hereditary material is stored inside the cell. Summers details how the first observations of mitosis and meiosis led to the formulation of the chromosome theory and the gene theory, and how both became combined, making scholars assume that the "Mendelian factors" or "genes" are located on chromosomes and transmitted vertically from parents to offspring. Nonetheless, cytologists also observed the cytoplasmic (lateral) transfer of nonchromosomal biochemical substances, "plasmagenes," which made them introduce theories on cytoplasmic inheritance. One such cytoplasmic biochemical substance that can be transferred laterally is the bacterial plasmid, which today we know is made up of circular DNA. Bacterial conjugation involves the lateral transfer of a plasmid-strand from a donor to a recipient bacterium.

Summers details how work on E. coli bacteria by Joshua and Esther Lederberg, Edward Tatum, Luigi Luca Cavalli-Sforza, William Hayes, and Allan Campbell led to the identification of plasmids and their lateral transmission by bacterial conjugation. The plasmid concept was first introduced by Joshua Lederberg in 1952, a year before the unravelling of the double helix, to designate "extrachromosomal hereditary particles." Lederberg's paper carries the title "Cell genetics and hereditary symbiosis," and he understood bacterial conjugation as one type of hereditary symbiosis.

Summers reviews how studies on plasmid transfer gave way to the discovery of the fertility factor (F-factor) necessary to induce bacterial conjugation, and how it became clear that genetic exchange can also occur between plasmid DNA and chromosomal DNA (e.g., in Hfr strains where the F-factor becomes part of the genome of $E$. coli).

In 1958, François Jacob and Elie Wollman introduced the episome concept, to identify "genetic elements which were optionally associated with the chromosomes of the cell" and Summers describes how, because of advanced knowledge into the biochemical nature of plasmids and episomes, the plasmid concept was favored over the episome concept.

Bacteria, and to a lesser extend Archaea, house many plasmids that are nontransferrable. Some of these can nonetheless become mobilized by other conjugative plasmids that reside inside the host cell, but around $48 \%$ of proteobacterial plasmids are neither conjugative, nor mobilizable, and thus always non-transferrable. These non-transferable plasmids contain genes that are not essential for the bacterial host, and the bacteria sometimes lose these plasmids over time or the plasmids undergo considerable gene loss. Many are nonetheless able to maintain their position. This poses an interesting scientific riddle: Are plasmids "selfish 
genes" that entail a fitness cost for their bacterial hosts and if so, does there exist selection against the presence of these non-transferrable plasmids towards plasmid-free cells; or is there instead selection towards the maintenance of a symbiotic relationship between the host and the plasmid?

In their chapter Symbiosis Between Non-Transferable Plasmids and Prokaryotic Cells, Francisco Dionisio, João Alves Gama, and André F.P. Carvalho detail how the prokaryotic organisms entertains a symbiotic relationship with the nonconjugative plasmids and how there can be selection for the maintenance of such relationship. By examining the selective mechanisms that underlie stable symbiotic associations between the host and the non-transferrable plasmid, the biologists provide a new means to understand the intricate interaction between symbiosis and natural selection.

From the chapter, we learn that there are more connections to be drawn between how neo-Darwinists and symbiologists approach their research subject. Dionisio, Alves Gama, and Carvalho apply sociobiology, especially "the public goods theory" to bacteria. Metaphorically speaking, a bacterium harboring plasmids can be considered a public entity or public space where different plasmid individuals (the goods of the public entity) compete over resources (the goods of the host) as well as the occupation of that space provided by the host. Most importantly, that public entity itself also sets rules on who can inhabit the niche and how the space is occupied. The reader is introduced to several trade-off scenarios and cost-benefit equations that help conceptualize the symbiotic association between plasmids and their host at the micro-organismal level.

The disease ecologist Caetano Souto-Maior explains how both symbiosis and lateral gene transfer provide innovative ways in which we can understand (1) host-symbiont relations, (2) symbiont-pathogen relations, and (3) pathogen-host relations as crucial for the transmission of infective disease. Many diseases are transmitted by vectors, i.e., symbiotic organisms that harbor pathogens which in turn infect the host of the symbiont. When these vectors endure long-lasting symbiotic associations with a host, both the vector (the symbiont) as well as the pathogens (residing inside the symbionts and affecting the host) can become vertically transmitted in the host lineage.

In his chapter, Host-Symbiont-Pathogen-Host Interactions: Wolbachia, VectorTransmitted Human Pathogens, and the Importance of Quantitative Models of Multipartite Coevolution, the author highlights several case studies. Different species of mosquitos and worms that parasitize humans often themselves carry various bacterial strains such as Wolbachia, or viruses such as the dengue virus, and both can cause disease in humans. Wolbachia infections have been implicated in various human diseases, including river blindness (van den Hurk et al. 2012) and elephantiasis (a lymphatic disease characterized by swellings of the lower limbs). The dengue virus causes dengue fever, a tropical blood disease that induces rashes, gastro-enteritis, muscle and joint pains, and potentially lethal fevers as well as potentially lethal hemorrhagic shock (the uncontrollable release of blood from the veins leading to severe bleedings). 
Wolbachia provide their host mosquito with protection against infection with the dengue virus, but Wolbachia also harm mosquitos by reducing their fitness and intervening in the sexual maturation of the female mosquito eggs (Kozek and Ramakrishna 2007; Hurst et al. 1999). With Wolbachia-infected mosquitos reduce the chance that the dengue virus infects mosquitos and that they in turn infect humans with the dengue disease via mosquito bites.

Experimental projects have been introduced whereby scholars intentionally infect the mosquitos prone to dengue infection with Wolbachia strains that are harmless to humans (see e.g., http://www.eliminatedengue.com). These mosquitos have subsequently been released in nature, with the hope to eradicate dengue fever infections in humans. Similar experiments have also been conducted with the hope to reduce the spread of yellow fever and the chikungunya virus (van den Hurk et al. 2012), as well as the West Nile virus (Hussain et al. 2013), which are all transmitted by mosquitos. Such genetic engineering can help eliminate infective disease.

Souto Maior furthermore details several cases of horizontal gene transfer between the Wolbachia genome and the host's nuclear genome. To understand these intricate and complex horizontal interactions between hosts, symbionts, and pathogens, the author illustrates how important it is to develop tri- and multipartite population dynamics. Evolutionary models, for the author, should include ecological, immunological, and epidemiological accounts on the interactions hosts, symbionts, and pathogens entertain. He furthermore emphasizes that most infections occur stochastically, and drift, more than natural selection theory should underlie population genetics and symbiology, as well as the epidemiology or spread of disease.

In the chapter Evolution of the Human Microbiome and Impacts on Human Health, Infectious Disease, and Hominid Evolution, the anthropologist Laura Weyrich exemplifies studies on the evolution of the human microbiome. Ancient feces (coprolite) provide insight into the evolution of the human gut microbiome, and calcified dental plaque gives knowledge on the various microorganisms that have populated the oral cavity. Weyrich demonstrates an intricate coevolution between lifestyle, microbiome, health, and disease.

She starts her chapter by comparing the human microbiome with the microbiome of our closest living relatives, the chimpanzees and bonobos, in order to reconstruct the microbiome of our last common ancestors. She subsequently compares incoming data on the microbiomes of Western urbanized, and Indigenous populations. Her overall conclusion is that the microbiome is ecologically determined: when populations share the same environment and thus the same food resources, they share the same microbiome.

The author then turns to more ancient human lineages. Using next-generation sequencing techniques (especially meta-barcoding), Weyrich, together with her colleagues at the Australian Centre for Ancient DNA, was able to identify the changes in the oral human microbiome over the past 8000 years. They found that especially the Neolithic Revolution (the onset of agriculture some 7500 years ago) 
and the Industrial Revolution (which occurred around 200 years ago) severely changed the human oral microbiome, mostly in negative ways.

The introduction of agriculture marks a transition from a hunter-gatherer lifestyle to a more sedentary lifestyle characterized by the domestication and cultivation of crops. While the introduction of agriculture is often characterized as a "great leap forward," Weyrich demonstrates that hunter gatherers fared much better healthwise than the early agriculturalists did. The ancient biofilms even enable Weyrich to infer when bacterial pathogens entered the human microbiome in time, and thus to infer when certain diseases started to plague humankind; and she can backtrack the coevolutionary process the microbiome has undergone with the human immune system.

The Industrial Revolution was characterized by the invention of the machine which in turn enabled the production of manufactured foods as well as the preservation of food products by pasteurization, sterilization, or canning. Polluted air from factories and metal poisoning are some of the negative consequences, while on the other hand, the industrialization also marks an end to famine that characterized Western societies for centuries. These events are also evidenced in shifts in the composition of the human microbiome, and the data show an intricate, commensalist coevolution between human hosts and microbial communities.

In the final parts of her chapter, Weyrich reviews how the hybridization that took place between early Homo sapiens species and Neanderthals and Denisovans (a sister taxa of Neanderthals), have impacted the evolution of the human microbiome, and how the microbiomes of the various species has in turn contributed to successful hybridization. In short, the human microbiome contributes to physical health, infectious disease, successful adaptation, hybridization, and possibly also extinction and speciation.

Michael Arnold, Amanda Brothers, Jennafer Hamlin, Sunni Taylor, and Noland Martin also take us to the Animal Kingdom and write on DivergenceWith-Gene-Flow-What Humans and Other Mammals Got up to. The authors define divergence with gene flow as "evolution of diverging populations with some amount of continued genetic exchange between them," and understand the concept as an alternative to the notion of hybridization that historically invokes negative connotations and assumptions on hybrid sterility or assumptions that hybrid genotypes induce a genetic burden on their carrier. The authors demonstrate that these assumptions are untenable. "Divergence with gene flow" furthermore enables the inclusion of incoming research on symbiosis and lateral gene transfer.

Arnold and coauthors prove that divergence with gene flow occurs abundantly in animal life. To make their case, the authors have chosen to baffle us with numerous case studies and scientific evidence of divergence with gene flow as it has been reported in scientific works since 2008. They in particular focus on the mammalian lineage and include data on our own species, Homo sapiens.

The authors give an impressive lineup that starts with the cooptation of retroviral DNA in early mammalian lineages and the role these viruses play in the formation of the placenta. Making their way through the mammalian tree, they illustrate divergence with gene flow in marsupials, mice, rats, chipmunks, hares and rabbits, 
shrews, minks, pole cats, polar and brown bears, panthers, wild cats, boars and domesticated pigs, wildebeest, chamois, deer species, marine mammals, horses, and bats. When turning to the primates, Arnold and coauthors note that the "clade in general is a rich source of examples of reticulate evolution." From Lemurs to Old World monkeys, numerous proofs exists for inter-taxa mating. Within our own Homo lineage, several subtaxa have mixed: there was admixture between Homo sapiens and $H$. neanderthalensis, and also various human sub-populations have introgressed with more archaic species, thereby incorporating Denisovan genes, as well as currently unidentified Melanesian, African, and European lineages of archaic $H$. sapiens. The authors emphasize that "these data falsify the hypothesis of simple replacement of archaic forms by our species and instead favor a scenario of mutual attraction and genetic exchange leading to a human genome that is a mosaic of recent and ancient DNA sequences."

Their case studies demonstrate that divergence with gene flow occurs abundantly and rapidly. Repeated divergence with gene flow does not, as a rule, lead to sterility. Most of the time, rather than pose a genetic burden on the mixing species, divergence with gene flow increases successful survival as well as speciation, it occurs more than sympatric or parapatric speciation, and divergence with gene flow contributes to biodiversity.

The authors conclude that reticulate evolution does not confine itself to lateral gene transfer between prokaryotes and hybridization between plants, it also occurs abundantly in animals, by both divergence with gene flow as well as lateral gene transfer. Along the way, the authors also introduce the reader to new scientific jargon as well as a series of innovative techniques and methodologies by which scholars can, beyond any reasonable doubt, make the case for understanding genetic exchange not as linear but reticulate and "web-like."

Evolutionary biology has greatly advanced by adopting bioinformatics and overall computational approaches that help test evolutionary hypotheses as well as model evolutionary scenarios. In their chapter A Multiset Model of Multi-Species Evolution to Solve Big Deceptive Problems, Luís Correia and António Manso demonstrate how reticulate evolution can be modelled artificially.

In previous work, the authors have developed a Multiset Genetic Algorithm (MuGA) that enables to model competitive multiple species evolution. Instead of depicting populations as a collection of individuals, in MuGA, the populations are represented as multisets (multi-populations), and the operators explore the multisets in order to optimize problems. Such multisets are not found in the natural world, but the models are interesting to examine engineering problems.

In this chapter, they present a variant of their model, SMuGA, which is a novel approach to artificial symbiosis. The model integrates symbiosis and lateral gene transfer with MuGA to model cooperative coevolutionary and symbiotic relations between hosts and parasites.

Their model is able to simulate symbiotic collaborations between a single host and multiple symbionts. More specifically, they model how a single host receives genetic material from multiple parasites with varying genome length, and they model the interaction between the multiple parasites and the host. They can 
investigate how artificial symbiogenetic evolution enables optimization of fitness calls, thereby accelerating optimization of deceptive problems.

The model has two phases: in the first phase, symbiotic interactions are generated and competition exists over the composition of the next generation of host population, and in the second phase, hosts and parasites first evolve independently, but the parasites compute their own fitness based upon the host's fitness which enables a computing of successful collaborations instead of actually generating them. Symbionts are thus enabled to "evaluate" and "explore" their host.

In general, it is hard to simulate real-life events because of the complexity involved. Symbiosis, symbiogenesis, and lateral gene transfer pose additional problems and challenges to be overcome by modelers, not in the least because of the numerous additional relations that need to be brought into the system. The authors present an innovative model as well as new techniques and methodologies, to model the complex interactions and integrations of symbionts and their genes into the host.

\section{Reticulate Evolution, the Modern, and the Extended Synthesis}

As this introduction makes clear, there are merely fine lines to be drawn between the various mechanisms whereby reticulate evolution can occur, and most of the time, the various mechanisms are simultaneously active within the same organisms.

Both symbiosis and symbiogenesis can impact the future course of evolution. Symbionts can become horizontally and vertically transmitted without inducing symbiogenesis. The major difference is that in symbiosis, the individuals maintain some form of individuality although both partners, and at a higher level also the populations they belong to, are affected by the symbiotic relation (which is the case with Wolbachia and their insect hosts, for example). Symbiogenesis occurs through a permanent form of hereditary and obligate symbiosis, whereby the partners start to become dependent upon one another, up to the point that they become a single new individual.

The easiest way to distinguish between lateral gene transfer and symbiosis or symbiogenesis is by following Margulis (1998) differentiation: lateral gene transfer is characterized by "gene fusions," while endosymbiosis is characterized by "cell fusions" or "body fusions." During horizontal gene transfer, the genes are not literally fused, but they are horizontally exchanged between distinctly evolved organisms, an exchange that leads to the insertion of foreign DNA into the recipient's genome. During symbiogenesis, not genes but whole cells or multicellular organismal bodies fuse, literally, one organism engulfs the other in its totality, and such a fusion leads to symbiogenesis. 
According to this distinction, also any type of meiotic, eukaryotic sex is primarily based upon endosymbiosis, and such a characterization in turn makes the line between hybridization and symbiogenesis or symbiosis more fluent. Per definition, hybridization always requires a form of sex. But sexual contact can be understood as a form of symbiosis or symbiogenesis, where the sex cells and genes come together into a new and stable individual. An example is human sexual reproduction where the male and female temporarily engage in a facultative form of conjunctive symbiosis; and upon fertilization, the head of the sperm cell permanently enters the egg cell. The haploid chromosomes of both cells form diploid pairs, and the zygote starts to differentiate into the various structures that make up the newly formed multicellular organism. Or as Margulis (1998: 40-42) put it: "Sex, too, is the coming together, the merging of cells of different histories and abilities. In sex the cells that fuse are closely related and the fusion is reversible; in serial endosymbiosis the cells that fuse are only distantly related, and the fusion is permanent."

Hybridization, by necessity, only occurs in sexual and thus eukaryotic organisms, while symbiogenesis is not confined to eukaryotic life forms, it also occurs in asexual individuals. The same goes for lateral gene transfer. It crosses all domains of life, and it occurs by asexual means.

Infectious heredity blurs the divide between the living and the non-living. Prions and viruses are not considered to be living entities or basic units of life. Nonetheless, they evolve by means of reticulate evolution. They affect the evolution of life, and they might also be the outcome of reticulate mechanisms themselves. The origin of viruses or genomes in general imply a combination of various genes into a hypercyclic structure. Prions obtain their structure from interactions between proteins and possibly also certain bacteria. Infectious heredity occurs through all known media of reticulate evolution and was introduced as a separate form to emphasize the important role it plays in health and disease, which in turn impacts the future course of evolution.

It is important to note that until recently, the various means whereby reticulate evolution occurs were studied from within varied disciplines. Just as communication was lacking between the founders of the Modern Synthesis and scholars who studied reticulate evolution, communication was also lacking between the scientists who studied hybridization, symbiosis, symbiogenesis, lateral gene transfer, and infectious heredity.

Studies on hybridization and symbiosis first arose in botany and zoology. From the very onset, symbiosis research has developed in close contact with ecological research fields, where the symbiotic association was interpreted as a behavioral phenomenon displayed by different organisms that entertain various contact modes (commensalism, parasitism, or mutualism).

With the introduction of symbiogenesis as an evolutionary mechanism, Merezhkowsky introduced symbiogenesis into evolutionary biology. Merezhkowsky also linked symbiosis and symbiogenesis with the then-rising fields of bacteriology and research on the origin of life, abiogenesis, and astrobiology. But his work was by and large ignored. 
Bacteriology and virology have from its very beginning been intricately related to the biomedical sciences, especially immunology and epidemiology. It was in this context that the modes of lateral gene transfer were first described. But until recently, the biomedical sciences did not engage in evolutionary studies because, rather than focusing on the past, they focused on the present (the ontogeny and etiology of disease) and the future (by finding cures that eradicate diseases).

Bacteriology and virology were the first fields that defined microbiology as a separate area of research. Microbiology also forms a bridge between evolutionary biology, (an)organic chemistry, and abiogenesis, because Archaea provide insight into the first life forms, as do viruses, that might have played a significant role in the (pre-)RNA world as well as the formation of the eukaryotic nucleus, in a symbiogenetic fashion. In fact, it was the study of bacterial transformation that first evidenced that genes are the seats of heredity, insights that contributed to the rise of molecular genetics.

Cytoplasmic biology has brought to light that extrachromosomal structures such as plasmids and organelles exist and that extrachromosomal heredity plays a significant role in the evolution of life.

Nonetheless, at the turn of the twentieth century, botany, zoology, ecology, ethology, bacteriology, virology, astrobiology, cytoplasmic biology, developmental biology, epigenetics, and the biomedical sciences, were distinct research areas with little interdisciplinary contact. Besides zoology and to a lesser extend botany, these epistemic fields evolved separately from overall evolutionary theory. Symbiosis and symbiogenesis, or ecology, epigenetics, and developmental biology find their historical beginnings in a period designated by Julian Huxley as the "eclipse of Darwin." Research on cytoplasmic heredity, the mechanisms of lateral gene transfer, and the impacts of infectious heredity date back to the beginnings of the twentieth century, but the disciplines matured their theoretical and evidential frameworks outside or in the margins of the standard neo-Darwinian paradigm.

It is only in recent years that recognition of their significant data became wellreceived and that scholars are developing inter- and transdisciplinary practices that enable them to cross field-specific boundaries. The main reason for this is that the molecular phylogenetic reconstructions of the tree of life, that were based exclusively on neo-Darwinian frameworks, have led to anomalies that can only be explained by accepting reticulate evolution as a fact of life. Molecular phylogenetics in turn combines bioinformatics and computational evolutionary approaches.

The current challenges we are faced with are (1) to combine these emerging reticulate theories into encompassing reticulate evolutionary paradigms and (2) to integrate reticulate evolutionary theories with the existing theories on natural selection and drift into a more encompassing evolutionary synthesis.

Today, reticulate evolutionary mechanisms themselves are becoming combined into unifying frameworks, and such unification in turn provides a means to unify zoological and botanical evolutionary biology with molecular genetics, cell biology, microbiology, virology, mycology, ecology, developmental biology and epigenetics, and the biomedical sciences. Reticulate evolution also provides new methodologies and theoretical frameworks to investigate and understand old 
evolutionary problems, it enables innovative means for biochemical and genetic engineering, and it opens up intriguing ways to personalize medicine.

Even the sociocultural and linguistic sciences are applying key concepts of reticulate evolution to understand complex behavioral and sociocultural phenomena, and in turn, reticulate scholars are beginning to integrate sociocultural studies to understand the behavioral and biochemical communication and interaction that underlies symbiosis, symbiogenesis, hybridization, lateral gene transfer, and infectious heredity.

Neo-Darwinian theory has made significant progress by understanding not only anatomical form, but also the behavior of animals as outcomes of natural selection. Beginning with sociobiology, scholars have been able to extend the evolutionary framework towards the sociocultural and behavioral sciences, by understanding differential phenotypic behavior as the outcome of social or cultural learning. Sociobiological and behavioral theories are today applied within bacteriology and microbiology. Microorganisms do not have a brain, but they nonetheless display differential phenotypic behavior that is relevant from an ecological point of view. Communication need not involve spoken or signed language, it can also be of a biochemical kind.

Reticulate evolution also raises fascinating questions on units and levels of selection as well as cooperation that extend the individual towards higher ranks such as the group, bacterial types, colonies, or species. This necessitates an ecological and overall hierarchical approach to evolution that enables scholars to conceptualize how individual and group behavior, higher and lower-level evolution, as well as higher- and lower-level interactions occur.

Turning to the second challenge, the neo-Darwinian synthesis combines Darwin's mechanism of natural selection with Mendelian hereditary laws, chromosome and gene theories, aspects of mutation theories, and insights from theoretical and experimental population genetics. This theoretical effort has brought forth a standard paradigm according to which we can understand vertical evolution: the Modern Synthesis. The Modern Synthesis has helped explain why the tree of life, and especially the evolution of eukaryotic animal and plant life, takes on a vertical pattern of descent with modification, a splitting pattern characterized by the bifurcation and ramification of evolutionary lineages.

When we compare insights on reticulate evolution with the standard neo-Darwinian text books, it reads very much as science fiction. Nonetheless, reticulate evolution has and continues to be a determining factor in the evolution of life. It brings forth a pattern of intricate mergings in the tree of life that takes on net and web-like shapes when we cartography the crossings.

Reticulate evolution and vertical evolution induced by mutation, drift, natural selection, and migration are often theorized to be complementary principles, where natural selection and drift are hypothesized to follow after symbiosis or symbiogenesis took place. Scholars such as Merezhkowsky, Wallin, Kozo-Polyanski, or Margulis understood symbiosis as the primary source of evolutionary novelty, and natural selection was a secondary principle that acted upon 
the novel variation introduced by symbiogenesis. For them, natural selection was (merely) a weeding-out mechanism.

Both neo-Darwinians and early symbiologists alike have also often opposed themselves in "either/or" debates and have understood vertical and reticulate mechanisms as mutually exclusive principles. In practice, however, life evolves according to numerous evolutionary mechanisms, and they simultaneously influence the organism and higher ranks of life at multiple levels. Eukaryotic organisms incorporate organelles that evolved by means of symbiogenesis, which was the result of an intricate symbiosis of the original merging individuals. These eukaryotic organisms also evolved according to selectionist principles that underlie the vast biodiversity that characterizes the tree of life. Nonetheless, the eukaryotic organisms can become infected by microbiota, and during ontogeny, numerous symbiotic associations are entertained by all living organisms.

The future therefore consists of finding out how these various evolutionary mechanisms simultaneously bring forth the evolution of life. At a meta-level, we therefore need to ask how these mechanisms interact, and whether or not there is a higher-order sorting of evolutionary mechanisms. Does evolution sometimes favor selection over symbiogenesis, hybridization over symbiosis, or infectious heredity over lateral gene transfer? Or is there sometimes selection for reticulate evolution, or does reticulate evolution induce selection? What would induce such higher-order sorting? Is it the nature of the organism, the type of group it belongs to, or the environments the various taxa inhabit? These are questions that need to be tackled by a future generation of researchers. At present, we do not know and we also lack the epistemic frameworks to adequately frame the questions.

We live in an age of fascinating new discoveries and data collection, similar to the exiting times the early naturalists lived through when they first started to detail the adaptive behaviors and anatomical traits of animal life.

Data on reticulate evolution is currently ahead of theory and understanding. Integrating reticulate evolution into the overall existing evolutionary framework will undo many of the assumptions the latter once made. How we define organisms, groups, species, genera, or higher taxa requires reconceptualization that takes the numerous interactions that exist between organisms into account. It requires a basic reformulation of notions such as behavior, communication, fitness, adaptation, speciation, and extinction. Reticulate evolution has identified new units of evolution (such as hybrids, mobile genetic elements, symbionts, and holobionts), as well as levels of evolution. The "environment" is both abiotic as well as biotic. A multicellular organism is itself an entire community, from the intragenetic and intracellular level all the way up to the outer layers that bound it.

Whether it is possible to synthesize reticulate with vertical evolution into a revised evolutionary synthesis remains an unanswered question. Some scholars plead for an integration and a revision of the synthesis, others deny the possibility and call out for a rupture with the Modern Synthesis. Only the future will tell and though this volume is (merely) of an introductory level, we do hope it will inspire scholars to engage in finding the answers to these fascinating questions. 
Acknowlegements This work was written with the support of the Portuguese Fund for Scientific Research (grant ID SFRH/BPD/89195/2012 and project number UID/FIL/00678/2013) and the John Templeton Foundation (grant ID 36288).

\section{Glossary}

Aerobe organisms Organisms that require gaseous oxygen to metabolize. Compare to anaerobes

Algae (Aquatic) eukaryotic organisms that photosynthesize

Anaerobe organisms Organisms that are poisoned by gaseous oxygen and that live in oxygen-low or oxygen-free environments. Compare to aerobes

Archaea First domain of life, previously designated as Archaeabacteria in the kingdom of Monera

Axoneme Shaft of undulipodia

Bacteria Second domain of life, previously designated as Eubacteria in the kingdom of Monera

Bacteriophage Virus that infects bacteria

Centrioli Cylindrical cell organelle, found in pairs (together called the centrosome) in many eukaryotic organisms, built up from microtubules (tubulin protein structures) structured according to a $[9(3)+0]$ pattern. They help build the mitotic spindle that separates the chromosomes during division. Compare to undulipodia and cilia

Chloroplasts Organelles found in plant cells that have evolved by symbiogenesis from photosynthesizing cyanobacteria, currently enabling cells to photosynthesize

Cilium/Cilia Type of undulipodium that visually appears as hairs on the cell and functions as sensory organelles, often enabling motility. Their basal body has a $[9(3)+0]$ microtubular structure, and their shaft a $[9(2)+2]$ one. Compare to undulipodia and centrioli

Coevolution Process whereby distinct species reciprocally influence each other's future course of evolution

Computational evolution Field in computer science and artificial intelligence that develops computational models to investigate evolutionary problems

Cyanobacteria Chlorophyll pigment-containing and photosynthetic bacteria, previously known as blue-green algae, but algae are eukaryotes, while cyanobacteria are prokaryotes

Cytoplasm Cell liquid

Domains of life/3-domain classification According to Carl Woese, and based upon comparative molecular phylogenetics (in particular comparisons of sections of ribosomal RNA), life is classifiable into 3 major domains: Archaea, Bacteria and Eukaryota. This undoes the previous 5-kingdom classification

Eukaryota The third domain of life, consisting of protists, fungi, plants, and animals. Eukaryotes can be unicellular or multicellular organisms. Their distinctive feature is that their cells have nucleated genomes where the genes are packaged into separate chromosomes. Besides a nucleus, the cells of these organisms often also contain organelles, organlike structures such as mitochondria and chloroplasts, peroxisomes, and Golgi that associate with specific metabolic functions

Flagellum/Flagella Bacterial motile extensions made up of flagellin protein 
Fitness Reproductive success, measured by the number of offspring

Five-kingdom classification of life According to Whitaker and Margulis, and based upon the 3 symbiogenetic mergings proposed by the serial endosymbiotic theory, life can be classified into 5 kingdoms: prokaryotic Monera (that contain the Archaebacteria, and Eubacteria) and the eukaryotic Protoctist (alternatively known as Protists, Rothschild 1989), Fungi, Plant, and Animal kingdoms

Fungi An eukaryotic kingdom of life that evolved after archaea, bacteria, and protists, and distinct from animals and plants. They contain microorganisms such as yeast and molds, but also larger organisms such as mushrooms

Germ theory of disease Theories first introduced by scholars such as Pasteur and Koch that indentify microorganisms as causal agents of disease

Holobiont Term first introduced by Margulis and Fester (1991) to designate an organism and its symbiotically associating partners

Horizontal transmission Any type of exchange between distinct individuals that happens during their lifetime and outside of the germ line (in a non-Mendelian fashion)

Host The larger partner in a symbiotic association

Jumping genes Genes that can switch position in the genome they are part of, as well as travel to adjacent intracellular genomes (neighboring organelles for example), thereby causing deletions, insertions, and duplications in turn responsible for mutations, malfunctions, or the introduction of novel traits. Today known as transposons

Kinetosomes Basal body of undulipodia

Microbiome The complete ecological community of microorganisms that inhabit a species. Compare to viriome

Microtubules Polymers (strings) of tubulin proteins

Mitochondria Eukaryotic cell organelles that evolved from aerobe proteobacteria by symbiogenesis, functionally resembling power factories because they produce and store energy

Modern Synthesis The standard evolutionary paradigm that unites (aspects of) Darwinian selection theory with Mendelian hereditary laws, Boveri-Sutton's chromosome theory; Weismann's vertical hereditary descent theory; and de Vries' and others' mutation theory to explain the evolution of life. Alternatively known as neo-Darwinism

Monera Taxonomic unit previously known as the first Kingdom of life, subdivided into Archaeand Eubacteria

Nucleoid Prokaryotic genome, not bounded by a membrane, not packaged into separate chromosomes. Compare to nucleus

Nucleus Membrane-bounded cell organelle that contains DNA packaged into separate chromosomes, only present in eukaryotes

Pathogens Disease-causing agents such as bacteria, bacteriophages, viruses, prions, fungi, and other protozoan microorganisms

Phagocytosis The act of "eating" whereby a cell engulfs a solid particle that either becomes an organelle or vesicle

Phylogenetics The systematic study of the evolutionary relationship amongst species, phyla, and higher taxa 
Plasmid Extrachromosomal, often circular DNA, often the seat of antibiotic resistance genes and crucial for bacterial conjugation

Prions Infectious pathogenic proteins

Prokaryotes All organisms that neither have a membrane-bounded nucleus nor organelles inside their cell. Instead, their genome floats freely inside the cytoplasm in a structure called the nucleoid

Speciation The origin of new species out of old ones, induced by evolutionary mechanisms including, among others, symbiogenesis, lateral gene transfer, hybridization, drift, virolution and natural selection; biotic factors including geographical barriers or species-mate recognition factors; and abiotic factors such as climate change

Spirochetes A phylum of gram-negative, anaerobe, double-membraned, corkscrew-shaped, mobile bacteria

Symbiont The smaller partner in a symbiotic association

Thermoplasma A genus of Archaea (prokaryotes), consisting of anaerobe and fermenting microorganisms

Undulipodium/undulipodia Motile extension of eukaryotic cells, visually resembling a tail. Undulipodia are typified by their $[9(2)+2]$ microtubullar pattern in their shaft (called the axoneme) and a [9(3) + 0] pattern in their basal body (called the kinetosome). They are similar and presumed evolutionary homologous to eukaryotic centrioli and cilia, and distinct from bacterial flagella. Compare to cilia and centrioli

Vector Any organism that functions as a medium for the distribution of pathogens or microorganisms

Viriome All viruses infectious for, and viral parts present in, a certain species. Compare tomicrobiome

Virus Infectious genetic agent

\section{References}

Anderson E (1949) Introgressive hybridization. John Wiley, New York

Anderson E, Stebbins GL Jr (1954) Hybridization as an evolutionary stimulus. Evolution 8:378-388

Albany M (1998) Conjunctive symbiosis. A Dictionary of Plant Sciences. http://www. encyclopedia.com

Archibald JM (2011) Origin of eukaryotic cells: 40 years on. Symbiosis 54:69-86

Archibald J (2014) One plus one equals one: symbiosis and the evolution of complex life. Oxford University Press, New York

Archibald JM, Richards TA (2010) Gene transfer: anything goes in plant mitochondria. BMC Biol 8:147

Arnold M (1997) Natural hybridization and evolution. Oxford University Press, New York

Arnold M (2004) Transfer and origin of adaptations through natural hybridization: were Anderson and Stebbins right? Plant Cell 16:562-570

Arnold M (2006) Evolution through genetic exchange. Oxford University Press, New York

Babcock EB, Stebbins GL (1938) The American species of crepis: their interrelationships and distribution as affected by polyploidy and apomixis. Carnegie Institution of Washington, Washington DC 
Backhed F, Ley RE, Sonnenburg JL, Peterson DA, Gordon JI (2005) Host-bacterial mutualism in the human intestine. Science 307:1915 doi: 10.1126/science.1104816

Bapteste E (2014) The origins of microbial adaptations: how introgressive descent, egalitarian evolutionary transitions and expanded kin selection shape the network of life. Front Microbiol 3(5):83

Bapteste E, Susko E, Leigh J, MacLeod D, Charlebois RL, Doolittle WF (2005) Do orthologous gene phylogenies really support tree-thinking? BMC Evol Biol 5(1):33. doi:10.1186/1471-2148-5-33

Bastian FO, Sanders DE, Forbes WA et al (2007) Spiroplasma spp. from transmissible spongiform encephalopathy brains or ticks induce spongiform encephalopathy in ruminants. J Med Microbiol 56(9):1235-1242. doi:10.1099/jmm.0.47159-0

Blanchard JL, Lynch M (2000) Organellar genes: why do they end up in the nucleus? Trends Genet 16(7):315-320. doi:10.1016/S0168-9525(00)02053-9

Bonen L, Doolittle WF (1975) On the prokaryotic nature of red algal chloroplasts. PNAS 72(6):2310-2314

Bonen L, Doolittle WF (1976) Partial sequences of 16s rRNA and the phylogeny of blue-green algae and chloroplasts. Nature 261:669-673. doi:10.1038/261669a0

Bonen L, Cunningham RS, Gray MW, Doolittle WF (1977) Wheat embryo mitochondrial 18s ribosomal RNA: evidence for its prokaryotic nature. Nucleic Acids Res 4(3):663-671

Bravo JA, Julio-Pieper M, Forsythe P, Kunze W, Dinan TG, Bienenstock J, Cryan KF (2012) Communication between gastrointestinal bacteria and the nervous system. Curr Opin Pharmacol 12:6667-6672. doi:10.1016/j.coph.2012.09.010

Brucker RM, Bordenstein SR (2012) Speciation by symbiosis. Trends Ecol Evol 27(8):443-451

Buchner P (1921) Tier und Pflanze in intrazellularer Symbiose, Berlin

Buchner P (1939) Symbiose der Tiere mit pflanzlichen Mikroorganismen, Berlin

Campbell PD (2007-2015) The Germ theory calender. http://germtheorycalendar.com/

Carrapiço F (2006) The origins of life and the mechanisms of biological evolution. In: Proceedings of SPIE 6309: 630900-1-630900-5

Cowles HC (1915) Hereditary symbiosis. Bot. Gaz. 59(1):61-63

De Bary HA (1878) Über symbiose. Tageblatt 51 Versamml. Deutscher Naturforscher u. Aerzte, Cassel 121-126

De Duve C, De Barsy T, Poole B, Trouet A, Tulkens P, Van Hoof F (1974) Commentary: lysosomotropic agents. Biochem Pharmacol 23(18):2495-2531

Dole M (1965) The natural history of oxygen. J Gen Physiol 49(1) Suppl: 5-27. doi:10.1085/ jgp.49.1.5

Doolittle FW (2000) Uprooting the Tree of life. SCIAM 282(2):72-77. doi:10.1038/scientificam erican $0200-90$

Douglas AE (2010) The symbiotic habit. Princeton University Press, New Jersey

Dunning Hotopp JC, Clark ME, Oliveira DCSG et al (2007) Widespread lateral gene transfer from intracellular bacteria to multicellular eukaryotes. Science 317(5845):1753-1756. doi:10.1126/science. 1142490

Engels WR, Preston CR (1981) Identifying P factors in Drosophila by means of chromosome breakage hotspots. Cell 26(3):421-428

Finnegan DJ (1989) Eukaryotic transposable elements and genome evolution. Trends Genet 5:103-107

Flannery DT, Walter RM (2012) Archean tufted microbial mats and the great oxidation event: new insights into an ancient problem. Austr J Earth Scien 59(1):1-11. doi:10.1080/0812009 9.2011.607849

Flavell AJ (1981) Did retroviruses evolve from transposable elements? Nature 289:10-11

Foster JA, McVey Neufeld KA (2013) Gut-brain axis: how the microbiome influences anxiety and depression. Trends Neurosci 36(5):305-312. doi:10.1016/j.tins.2013.01.005

Frost LS, Leplae R, Summers AO, Toussaint A (2005) Mobile genetic elements: the agents of open source evolution. Nat Rev of Microbiology 3:722-732 
Gaudillière JP, Löwly I (eds) (2001) Heredity and infection: the history of disease transmission. Cermes, Paris and Routledge, London

Gifford R, Tristem M (2003) The evolution, distribution and diversity of endogenous retroviruses. Virus Genes 26(3):291-315. doi:10.1023/A:1024455415443

Gogarten P (2000) Horizontal gene transfer: a new paradigm for biology. In: Esalen Center for Theory and Research Conference

Gontier N (2006) Evolutionary epistemology and the origin and evolution of language: taking symbiogenesis seriously. In Gontier N, Van Bendegem JP, Aerts D (eds) Evolutionary epistemology, language and culture. Springer, Dordrecht, pp 195-2260

Gontier N (2007) Universal symbiogenesis: an alternative to universal selectionist accounts of evolution. Symbiosis 44:167-181

Gontier N (forthcoming) Uniting micro- with macroevolution into an extended synthesis: reintegrating life's natural history into evolution studies. In: Serrelli E, Gontier N (eds) Macroevolution. Springer, Dordrecht, p 227

Gontier N (forthcoming) Symbiosis and symbiogenesis. In Kliman RM (ed) Encyclopedia of evolutionary biology. Elsevier, London

Haldane JBS (1949) Disease and evolution. Ric Sci Suppl A 19:68-76

Harrison RG (1990) Hybrid zones: windows on evolutionary process. Oxford Surv Evolution Biol 7:69-128

Holland HD (2006) The oxygenation of the atmosphere and oceans. Phil Trans R Soc B 361:903-915

Hurst G, Jiggins FM, Graf von Der Schulenburg JH, Bertrand D et al (1999) Male killing Wolbachia in two species of insects. Proc R Soc B 266(1420):735-740. doi:10.1098/r spb.1999.0698

Hussain M, Lu G, Torres S, Edmonds JH (2013) Effect of Wolbachia on replication of West Nile virus in a mosquito cell line and adult mosquitoes. J Virol. doi:10.1128/JVI.01837-12/

Kazazian HH Jr et al (1988) Haemophilia A resulting from de novo insertion of L1 sequences represents a novel mechanism for mutation in man. Nature 332(6160):164-166

Kingsbury N (2009) Hybrid: the history and science of plant breeding. University of Chicago Press, Chicago

Knerr I, Beinder E, Rascher W (2002) Syncetin, a novel human endogenous retroviral gene in human placenta: evidence for its dysregulation in preeclampsia and HELLP syndrome. Am J Obstet Gynecol 186(2):210-213. doi:10.1067/mob.2002.119636

Kozek WJ, Ramakrishna RU (2007) The discovery of Wolbachia in arthropods and nematodesa historical perspective. Issues in Infectious Diseases 5:1-14. doi:10.1159/000104228

Lederberg J (1952) Cell genetics and hereditary symbiosis. Physiol Rev 32(4):403-430

Lederberg J (1998) Personal perspective: plasmid (1952-1997). Plasmid 39:1-9

Lederberg J (1999) JBS Haldane (1949) on infectious disease and evolution. Genetics 1(153):1-3

Lederberg J (2003) Infectious history. Science 288(5464): 27

Lederberg J, Lederberg EM (1956) Infection and heredity. Symp Soc Growth Develop 14:101-124

Lederberg J, McCray AT (2001) Ome sweet 'omics—a genealogical treasury of words. Scientist $15: 8$

Ley R (2010) Obesity and the human microbiome. C Opinion Gastroent 26(1):5-11. doi:10.1097 /MOG.0b013e328333d751

Ley RE, Peterson DA, Gordon JI (2006) Ecological and evolutionary forces shaping microbial diversity in the human intestine. Cell 124:837-848. doi:10.1016/j.cell.2006.02.017

Linnaeus C (1753 Species plantarum (2 volumes). Holmiae: Impensis Laurentii Salvii http://dx. doi.org/10.5962/bhl.title.669

Livingstone Bell PJ (2001) Viral eukaryogenesis: was the ancestor of the nucleus a complex DNA virus? J Mol Evol 53(3):251-256. doi:10.1007/s002390010215

López-Caamal II A, Tovar-Sánchez E (2014) Genetic, morphological, and chemical patterns of plant hybridization. Rev chil hist nat Santiago 87 doi:10.1186/s40693-014-0016-0 
Lovelock J (1972) Gaia as seen through the atmosphere. Atmos Environ 6:579-580

Lovelock JE, Margulis L (1974) Atmospheric homeostasis by and for the biosphere: the Gaia hypothesis. Tellus Series A 26(1-2): 2-10 (Stockholm: International Meteorological Institute)

Löwer R, Löwer J, Kurth R (1996) The viruses in all of us: characteristics and biological significance of human endogenous retrovirus sequences. Proc Natl Acad Sci USA 93(11):5177-5184

Mallet J (2005) Hybridization as an invasion of the genome. Trends Ecol Evol 20:229-237

Mallet J (2007) Hybrid speciation. Nature 446:279-283

Marchi E et al (2013) Neanderthal and Denisovan retroviruses in modern humans. Curr Biol 23(22):R994-R995

Margulis L (1970) Origin of eukaryotic cells. Yale University Press, New Haven

Margulis L (1998) The symbiotic planet: a new look at evolution. Weidenfeld \& Nicolson, London

Margulis L (ed) (1991) Symbiosis as a source of evolutionary innovation: speciation and morphogenesis. The MIT Press, Boston

Margulis L, Dolan MF (2001) Early life. Jones \& Bartlett Publishers International, Sudbury

Margulis L, Fester R (1991) Symbiosis as a source of evolutionary innovation: speciation and morphogenesis. MIT Press, Boston

Margulis L, Dolan MF, Guerrero R (2000) The chimeric eukaryote: origin of the nucleus from the karyomastigont in amitochondriate protists. PNAS 97(13):6954-6959

Margulis L, Chapman M, Guerrero R, Hall J (2006) The last eukaryotic common ancestor (LECA): acquisition of cytoskeletal motility from aerotolerant spirochetes in the Proterozoic Eon. PNAS 103(35):13080-13085

Martin W, Herrmann RG (1998) Gene transfer from organelles to the nucleus: how much, what happens, and why? Plant Physiol 118(1):9-17

Maxmen A (2010) Virus-like particles speed bacterial evolution. Nature. doi:10.1038/ news.2010.507

Mayr E (1942) Systematics and the origin of species, from the viewpoint of a zoologist. Harvard University Press, Cambridge

McClintock B (1950) The origin and behavior of mutable loci in maize. Proc Natl Acad Sci USA 36(6):344-355

McClintock B (1953) Induction of instability at selected loci in maize. Genetics 38(6):579-599

Melezhik VA (2006) Multiple causes of earth's earliest global glaciation. Terra Nova 18(2):130 137. doi:10.1111/j.1365-3121.2006.00672.x

Nelson PN, Hooley P, Molecular Immunology Research Group (2004) Human endogenous retroviruses: transposable elements with potential ? Clin Exp Immunol 138(1):1-9. doi:10.1111/j.1365-2249.2004.02592.x

Paracer S, Ahmadjian V (1986) Symbiosis: an introduction to biological associations. New England University Press, England

Pentecost A, Franke U (2010) Photosynthesis and calcification of the stromatolitic freshwater cyanobacterium rivularia. Eur J Phycol 45(4):345-353. doi:10.1080/09670262.2010.4929 14

Pietilä MK, Demina TA, Atanasova NS, Oksanen HM, Bamford DH (2014) Archaeal viruses and bacteriophages: comparisons and contrasts. Trends Microbiol 22(6):334-344. doi:10.1016/j. tim.2014.02.007

Pound R (1893) Symbiosis and mutualism. Am Nat 27:509-520

Prusiner SB (1982) Novel proteinaceous infectious particles cause Scrapie. Science 216(4542):136-144. doi:10.1126/science.6801762

Prusiner SB (1991) Molecular biology of prion diseases. Science 252(5012):1515-1522. doi:10.1126/science. 1675487

Rieseberg LH (1995) The role of hybridization in evolution: old wine in new skins. Amer J Bot 82:944-953 
Rieseberg LH (2001) Hybrid speciation. eLS, Wiley, New York. doi:10.1038/npg.els.0001753

Robert E, Kopp J, Kirschvink L, Hilburn IA, Nash C (2005) The Paleoproterozoic snowball earth: a climate disaster triggered by the evolution of oxygenic photosynthesis. Proc Natl Acad Sci USA 102(32):11131-11136. doi:10.1073/pnas.0504878102

Roberts HF (1929) Plant hybridization before Mendel. Princeton, New Jersey

Roossinck MJ (2012) Even viruses can be beneficial microbes. Microbiol Austr 33:111-112

Rothschild LJ (1989) Protozoa, protista, protoctista: what's in a name? JHist Biol 22(2):277-305

Rubin GM, Spradling AC (1982) Genetic transformation of Drosophila with transposable element vectors. Science 218(4570):348-353

Ryan FP (2005) Human endogenous retroviruses in health and disease: a symbiotic perspective. J R Soc Medicine 97(12):560-565

Ryan FP (2006) Genomic creativity and natural selection: a modern synthesis. B J Linnean Soc 88(4):655-672

Ryan FP (2009) Virolution. Harper Collins, London

Sagan L (1967) On the origin of mitosing cells. J Theor Biol 14:225-274

SanMiguel P, Tikhonov A, Jin YK et al (1996) Nested retrotransposons in the intergenic regions of the maize genome. Science 274(5288):765-768. doi:10.1126/science

Sapp J (1994) Evolution by association: a history of symbiosis. Oxford University Press, New York

Sapp J (2003) Genesis: The evolution of biology. Oxford University Press, New York

Sapp J (2009) The new foundations of evolution: on the tree of life. Oxford University Press, New York

Schneider A (1897) The phenomena of symbiosis. Minnesota Bot Stud 1:923-948

Shapiro J (1969) Mutations caused by the insertion of genetic material into the galactose operon of Escherichia coli. J Molec Biol 40:93-109

Shapiro JA (ed) (1983) Mobile genetic elements. Academic Press, London

Siefert JL (2009) Defining the Mobilome. In: Gogarten MB, Gogarten JP, Olendzenski LC (eds) Horizontal gene transfer: genomes in flux. Humana Press, Springer, Dordrecht

Singer MF (1982) SINEs and LINEs: highly repeated short and long interspersed sequences in mammalian genomes. Cell 28(3):433-444. doi:10.1016/0092-8674(82)90194-5

Smocovitis VB, Ayala FJ (2000) George Ledyard Stebbins. Biogr Mem Nat Acad Sci 85:290-313

Smocovitis VB (1997) G. Ledyard Stebbins, Jr. and the evolutionary synthesis (1924-1950). Am J Bot 84(12):1625-1637

Stanton TB (2007) Prophage-like gene transfer agents-novel mechanisms of gene exchange for Methanococcus, Desulfovibrio, Brachyspira, and Rhodobacter species. Anaerobe 13(2):43-49

Stebbins GL (1940) The significance of polyploid plants in plant evolution. Am Nat 74(750):54-66

Stebbins GL (1950) Variation and evolution in plants. Columbia University biological series 16, New York

Stebbins GL (1959) The role of hybridization in evolution. P Am Philos Soc 103:231-251

Sugimoto J, Schust DJ (2009) Review: human endogenous retroviruses and the placenta. Reprod Sci. 16(11):1023-1033. doi:10.1177/1933719109336620

Taylor AL (1963) Bacteriophage-induced mutation in E. coli. Proc Natl Acad Sci USA 50(6):1043-1051

Temin HM (1980) Origin of retroviruses from cellular moveable genetic elements. Cell 21:599-600

The NIH HMP Working Group (2009) The NIH human microbiome project. Genome Res 19(12):2317-2323

Turnbaugh PJ, Ley RE, Hamady M, Fraser-Liggett CM, Knight R, Gordon JI (2007) The human microbiome project. Nature 449:804-810. doi:10.1038/nature06244

Turnbaugh PJ, Hamady M, Yatsunenko T et al (2009) A core gut microbiome in obese and lean twins. Nature 457(7228):480-484. doi:10.1038/nature07540 
van Beneden PJ (1873) Un mot sur la vie sociale des animaux inférieurs. Bull Acad R Belgique 2(36):779-796

van Beneden PJ (1875) Les comensaux et les parasites dans le règne animal. Biblio Sci Int, Paris

van den Hurk AF, Hall-Mendelin S, Pyke AT, Frentiu FD (2012) Impact of Wolbachia on infection with chikungunya and yellow fever viruses in the mosquito vector Aedes aegypti. PLoS Neg1 Trop Dis. doi:10.1371/journal.pntd.0001892

Venu I, Durisko Z, Xu J, Dukas R (2014) Social attraction mediated by fruit flies' microbiome. J Exp Biol 217:1346-1352. doi:10.1242/jeb.099648

Villarreal LP, Defilipps V (2000) A hypothesis for DNA viruses as the origin of eukaryotic replication proteins. J Virol 74(15):7079-7084

Villarreal LP, Witzany G (2010) Viruses are essential agents within the roots and stem of the tree of life. J Theor Biol:698-710

von Faber FC 1912 Das erbliche Zusammenleben von Bakterien und tropischen Pflanzen. Jahrbücher für wissensch Botanik 51:III

Wallin IE (1927) Symbionticism and the origin of species. Williams and Wilkins, Baltimore

Whittaker RH, Margulis L (1978) Protist classification and the kingdoms of organisms. Biosystems 10:3-18

Woese CR, Fox GE (1977) Phylogenetic structure of the prokaryotic domain: the primary kingdoms. PNAS 74(11):5088-5090. doi:10.1073/pnas.74.11.5088

Woese CR, Kandler O, Wheelis M (1990) Towards a natural system of organisms: proposal for the domains Archaea, Bacteria, and Eucarya. Proc Natl Acad Sci USA 87(12):4576-4579. doi:10.1073/pnas.87.12.4576

Woese CR, Magrum LJ, Fox GE (1978) Archaebacteria. J Mol Evol 11(3):245-251. doi:10.1007 /BF01734485

Zinder ND (1953) Infective heredity in bacteria. Cold Spring Harbor Symp Quant Biol 18:261-269

Zirkle C (1934) More records of plant hybridization before Köelreuter. J Hered 25:3-18

Zirkle C (1935) The beginnings of plant hybridization. Morris Arboretum Monographs 1. University of Pennsylvania Press, Philadelphia 